\title{
Role of Rho family GTPases in epithelial morphogenesis
}

\author{
Linda Van Aelst ${ }^{1,3}$ and Marc Symons ${ }^{2}$ \\ ${ }^{1}$ Cold Spring Harbor Laboratory, Cold Spring Harbor, New York 11724, USA; ${ }^{2}$ Center for Oncology and Cell Biology, North \\ Shore-Long Island Jewish Research Institute and Department of Surgery, North Shore-Long Island Jewish Medical Center, \\ Manhasset, New York 11030, USA
}

Epithelial cell sheets line the organ and body surfaces and the specialized barrier functions of these epithelia regulate the exchange of substances with the outside environment and between different body compartments. Epithelia play a role in a wide range of physiological processes such as digestion, excretion, and leukocyte trafficking. In addition, during development, some epithelia form transient primitive structures, including the neural tube and somites, which are essential for the development of more complex organs.

The establishment and maintenance of epithelial cell polarity is critical for the development and functioning of multicellular organisms (Nelson 2000). A multi-step model for the establishment of cell polarity has been proposed by Drubin and Nelson (1996). Cell polarity is initiated by a spatial cue, such as generated by cell-cell contact sites. This cue is interpreted and marked by the formation of signaling complexes that relay the spatial information to the actin cytoskeleton. Localized actin assembly then leads to the formation of a targeting patch, which functions to reinforce the initial cue. Subsequently, this cue can further be propagated via a reorganization of the microtubule cytoskeleton, which in turn causes a redistribution of the membrane trafficking apparatus.

In addition to actin cytoskeletal dynamics and vesicle trafficking, epithelial morphogenesis also depends on cell-substrate and cell-cell adhesion. Members of the Rho family of GTPases play essential roles in each of these processes (for reviews, see Hall 1998; Kaibuchi et al. 1999a,b; Braga 2000; Ellis and Mellor 2000; Schwartz and Shattil 2000; Ridley 2001a,b) and therefore it is not surprising to see that Rho GTPases have emerged as critical players at multiple stages of epithelial morphogenesis. In this review we will discuss the involvement of Rho family members in the development and maintenance of epithelial morphology and highlight recent advances in our understanding of the roles of these GTPases in the establishment of epithelial polarity. We

${ }^{3}$ Corresponding author.

E-MAIL vanaelst@cshl.org; FAX (516) 367-8815.

Article and publication are at http://www.genesdev.org/cgi/doi/10.1101/ gad.978802. will also discuss the participation of these GTPases in epithelial remodeling during wound-healing and epithelial-mesenchymal transitions.

As other members of the Ras superfamily, Rho GTPases cycle between a GDP-bound (inactive) state and a GTP-bound (active) state. In the active state, these GTPases relay signals from growth factors, cytokines, and adhesion molecules to regulate a wide range of biological processes, including actin cytoskeleton organization, transcriptional regulation, and vesicle trafficking (Van Aelst and D'Souza-Schorey 1997; Hall 1998).

The nucleotide state of Rho family proteins is controlled by three classes of regulatory proteins: guanine nucleotide exchange factors (GEFs), GTPase activating proteins (GAPs), and guanine nucleotide dissociation inhibitors (GDIs) (Boguski and McCormick 1993). GEFs catalyze the exchange of GDP for GTP by facilitating the release of GDP and transient stabilization of the nucleotide-free protein. GAPs promote the intrinsic GTP hydrolyzing activity of Rho proteins, thereby enhancing their conversion to the GDP-bound form. GDIs preferentially bind to GDP-bound GTPases and prevent spontaneous and GEF-catalyzed release of nucleotide, thereby maintaining the GTPases in the inactive state. Although activation of Rho GTPases in response to extracellular signals in principle could occur either via the activation of GEFs or inhibition of GAPs and GDIs, studies on oncogenic forms of GEFs suggest that nucleotide exchange is the rate-limiting step in GTPase activation.

The localized activation of GEFs is likely to be of critical importance in polarity establishment and morphogenesis. Localized control of GEFs and GTPases has been extensively characterized in the budding yeast Saccharomyces cerevisiae. Polarized growth is important at several stages of the budding yeast life cycle, including bud formation during vegetative growth and shmoo formation during mating. Recent genetic and biochemical analyses of the roles of the GTPase Cdc42 and its GEF Cdc24 in these processes has led to a model in which GEF activity is regulated in four distinct steps: GEF recruitment to the plasma membrane and subsequent activation, stabilization by adaptor proteins, and termination of signaling by GEF inactivation (Gulli and Peter 2001). Less is known about the regulation of GEFs in 
other organisms (Symons and Settleman 2000) and the budding yeast model may therefore serve as a more general paradigm for the analysis of localized GEF activation.

\section{Establishment of apical-basolateral polarity}

Epithelia can display two types of polarity, apical-basolateral and planar polarity (see below). Apical-basolateral polarity depends on the segregation of different protein and lipid constituents to the apical and basolateral membrane domains and is generated through direct interaction of the cell with its environment, for example, extracellular matrix and intercellular contacts (Eaton and Simons 1995; Yeaman et al. 1999|. Apical-basolateral polarity is critical for the function of transporting epithelia, such as those found in the kidney and gastrointestinal tract. These epithelia establish permeability barriers between distinct compartments and vectorial transport along the apical-basal axis enables the maintenance of ionic homeostasis.

Different types of cell-cell junctions can be distinguished in epithelia. Adherens junctions and desmosomes provide mechanical strength to the epithelial cell contacts. The tight junctions (zonula occludens) control the selective permeability of the epithelial layer to ions and small solutes (gate function). Tight junctions also prevent the free mixing of proteins and lipids of apical and basolateral membrane compartments (fence function). Finally, gap junctions allow the passage of chemicals between adjacent cells.

The formation of cell-cell junctions can be described as a sequence of discrete steps, an analysis that is largely based on the use of the calcium-switch model (Braga 2000). On addition of calcium, cadherins become competent for homophilic binding to cadherins of neighboring cells (step 1). This adhesive interaction leads to cadherin clustering at cell-cell contact sites in a process that remains poorly understood (step 2) (for review, see Adams and Nelson 1998). Cadherin clusters are immobilized and stabilized by interaction with the actin cytoskeleton (step 3). This is followed by a reorganization of the actin cytoskeleton involving a profound remodeling of the circumferential actin belt that typifies isolated cells in culture (step 4). Concomitant with step 4, basolateral transport vesicles are rerouted to targeting patches that are localized at the contacting membranes, where they dock and fuse. In the next stage, these targeting patches and the apical junctional complex /tight junction) become restricted to the apex of the lateral membrane, leading to the establishment of a fully polarized epithelial phenotype with distinct apical and basolateral membrane compartments (step 5).

\section{Adherens junctions}

Studies using a wide range of cell lines have demonstrated that inhibition of Rho by C3 transferase, a bacterial exoenzyme, interferes with the establishment of adherens junctions (Braga et al. 1997, 1999; Takaishi et al. 1997). Interestingly, inhibition of Rho causes removal of cadherins from junctions before significant changes in cell morphology (i.e., cell rounding and retraction) can be observed, suggesting that Rho may play a role in adherens junction formation by stimulating cadherin clustering (Braga et al. 1997, 1999). Rho also is thought to function in the intracellular targeting of proteins, such as c-Src and ERM (Fincham et al. 1996; Kotani et al. 1997; Shaw et al. 1998; Timpson et al. 2001). An alternative scenario for the role of Rho in adherens junction formation therefore could be that Rho recruits accessory proteins to nascent junctions.

The downstream signaling pathways that mediate the effect of Rho on adherens junctions largely remain to be elucidated. Adherens junction formation in keratinocytes has been shown to depend on the activity of the tyrosine kinase Fyn (Calautti et al. 1998). This effect is possibly mediated via phosphorylation of adherens junction proteins such as $\beta$ - and $\gamma$-catenins or p120-catenin. Recent studies have shown that constitutively active Rho stimulates Fyn tyrosine phosphorylation of catenins and cell-cell adhesion, and that Rho-induced phosphorylation of catenins is reduced in Fyn-deficient keratinocytes (Calautti et al. 2002). These results indicate that Fyn and possibly other Src family kinases can function downstream of Rho in the establishment of adherens junctions. A possible Rho effector that could mediate this function is PRK2, as PRK2 kinase activity increases with keratinocyte differentiation and overexpression of PRK2, like activated Rho, stimulates Fyn phosphorylation of catenins and cell-cell adhesion.

Early evidence for a role of Rac in the regulation of adherens junctions came from studies showing that expression of dominant negative Dracl inhibits actin assembly at adherens junctions in the developing wing disc epithelium in Drosophila (Eaton et al. 1995). In mammalian cells, Rac has been shown to be activated by E-cadherin-mediated cell-cell contact (Nakagawa et al. 2001; Noren et al. 2001; Kovacs et al. 2002) and Rac activity is necessary for the establishment of adherens junctions in epithelial and endothelial cells (Braga et al. 1997, 1999; Takaishi et al. 1997). Making use of an assay that presents the ectodomain of E-cadherin on a solid substrate, it was shown that both phosphatidylinositol 3-kinase $(\mathrm{PI} 3 \mathrm{~K})$ and $\mathrm{Rac}$ are recruited to nascent cadherin contacts and that Rac is activated in a biphasic manner. Interestingly, the early phase (15 min) is independent of PI3K activation, whereas the later phase $(30 \mathrm{~min})$ is abrogated by PI3K inhibitors (Kovacs et al. 2002).

Similar to the observations on the wing epithelium in Drosophila, inhibition of Rac activity interferes with the accumulation of polymerized actin at adherens junctions (Braga et al. 1997; Takaishi et al. 1997), suggesting that Rac may mediate the reorganization of the actin cytoskeleton that is necessary to stabilize cadherin receptors at cell-cell contact sites. Support for such a mechanism comes from observations showing that recruitment of actin to cadherins that are clustered by antibodies is specifically blocked by inhibition of Rac, but not Rho (Braga 
et al. 1997). It is interesting to note that Rac also functions in the clustering of integrin receptors (Hotchin and Hall 1995; D'Souza-Schorey et al. 1998; Rottner et al. 1999|, suggesting that it also could play a similar role in clustering of cadherins.

Rac activation leads to a dramatic reorganization of intercellular contacts in MDCK cells. Whereas in wildtype MDCK cells, tight contact is restricted to the apical area of lateral membranes, in cells expressing constitutively active Rac1 tight contact extends over the entire lateral membrane (Takaishi et al. 1997; Jou et al. 1998). In addition, the lateral membranes display extensive interdigitation. Interestingly, the effect of constitutive activation of Rac on adherens junctions dramatically depends on the cell type under investigation. In keratinocytes constitutively active Rac causes disassembly of adherens junctions (Braga et al. 2000), which is essentially the opposite of what is observed in MDCK cells (Hordijk et al. 1997; Sander et al. 1999). The molecular mechanisms that underlie this cell type dependence need to be clarified. It is important to note, however, that these differences in response to Rac activation are critical for the role of Rac in epithelial-mesenchymal transitions and invasion, as discussed below.

A downstream target of Rac that has been implicated in the regulation of adherens junctions is IQGAP (Kuroda et al. 1998). IQGAP is a binding partner of both Rac and Cdc42 and localizes to cell-cell junctions (Kuroda et al. 1996). IQGAP competes with $\alpha$-catenin for binding to $\beta$-catenin, and thereby can displace $\alpha$-catenin from E-cadherin complexes. These findings suggested a model in which IQGAP keeps E-cadherin complexes in a "weak adhesion" state and Rac/Cdc42 binding to IQGAP acts as a switch to promote a "strong adhesion" state (Kaibuchi et al. 1999b). This model, however, is not corroborated by the phenotype of IQGAP1-deficient mice (Li et al. 2000). Indeed, even in tissues that do not express IQGAP2, a protein with a high degree of homology to IQGAP1 (Brill et al. 1996), no obvious developmental defects could be detected.

The potential role of $\mathrm{Cdc} 42$ in the regulation of adherens junctions is less well documented as that for Rac. The effects of constitutively active Cdc42 in MDCK cells resemble those of activated Rac1, although the interdigitation of the lateral membranes is much less pronounced (Kodama et al. 1999). Similar to Rac, Cdc42 is activated by E-cadherin-mediated cell-cell contact in a PI3K-dependent fashion (Kim et al. 2000) and Cdc42 activity is necessary for E-cadherin-dependent cell interactions (Fukata et al. 1999). It is interesting to note, however, that in Drosophila expression of a dominant negative version of DCdc42 does not have any significant effect on cell-cell junctions in the developing wing disc epithelium (Eaton et al. 1995).

\section{Tight junctions}

Several studies have shown that Rho activity is essential for the proper functioning of tight junctions. Early work showed that inhibition of Rho by C3 transferase dis- places the tight-junction protein zonula occludens 1 (ZO-1) from junctions and increases the paracellular permeability of polarized human epithelial cells (Nusrat et al. 1995). Expression of dominant negative Rho in MDCK cells also abolishes the fence function of tight junctions in the absence of overt changes in tight junction organization or protein composition (Jou et al. 1998). The more pronounced effect of C3 transferase on tight junctions probably reflects the weaker inhibitory effect of the dominant negative mutant of Rho.

A downstream target of Rho that is likely to mediate tight junction control is the Rho-associated kinase (Rok), as chemical inhibition of this effector enhances the paracellular permeability of polarized intestinal epithelia (Walsh et al. 2001). Inhibition of Rok also interferes with the recruitment of ZO-1 and occludin to newly forming intercellular contacts in these cells, suggesting that Rho/ Rok signaling also plays a role in the assembly of tight junctions (Walsh et al. 2001).

It is interesting to note that expression of either dominant negative or constitutively active mutant forms of RhoA at relatively low levels perturbs both the gate and fence functions of tight junctions in MDCK cells (Jou et al. 1998). This observation as well as numerous other instances where both inhibition and constitutive activation of Rho GTPases interfere with the same biological function are often interpreted to imply that GTP hydrolysis is a necessary step in the regulation of this biological function (Symons and Settleman 2000). Another potential mechanism, however, could be that tight junction behavior critically depends on the level of RhoA activation or alternatively that the inhibitory effects of the dominant-negative and GTP-hydrolysis-defective mutants are caused by interference in distinct functions that cooperatively control tight junction properties. Support for the latter scenario comes from electron microscopy observations showing that expression of constitutively active RhoA inhibits the formation of protein strands in the tight junctions, whereas dominant negative RhoA does not significantly affect tight junction morphology (Jou et al. 1998).

As is the case for Rho, both dominant negative and constitutively active mutants of Racl interfere with gate and fence functions of tight junctions in MDCK cells (Jou et al. 1998). Interestingly, however, in contrast to the effect of expression of constitutively active RhoA, constitutively active Rac enhances tight junction strand formation. The signaling mechanisms that mediate the regulation of tight junctions by Rac remain to be elucidated. One possible mechanism is that Rac modulates tight junction properties via its effect on the dynamics of perijunctional actin filaments (Madara 1998).

The effects of dominant negative and constitutively active mutants of Cdc42 on the function and morphology of tight junctions in MDCK cells appears to be similar to that of the cognate mutants of Rac1. Both dominant negative and constitutively active mutants of Cdc42 perturb gate and fence functions and constitutive activation of Cdc42 induces the formation of junctions 
well below the position where tight junctions normally form (Rojas et al. 2001).

Insights into the signaling mechanisms that control tight junctions downstream of Cdc42 are emerging. Cdc42 binds to Par-6, an adapter protein that in turn binds to $\mathrm{PKC} \lambda / \iota$ or $\mathrm{PKC} \zeta$, the two members of the atypical protein kinase $\mathrm{C}(\mathrm{aPKC})$ subfamily (Joberty et al. 2000; Lin et al. 2000). Both Par-6 and either one of the aPKCs bind to an additional adapter protein, Par-3, forming a ternary complex (Fig. 1). In addition to being implicated in the establishment of epithelial tight junctions in mammals, this evolutionary conserved Par-aPKC complex plays a critical role in a large number of other processes that involve cell polarity. These include asymmetric cell division in the Caenorhabditis elegans one-cell embryo and Drosophila neuroblasts and the maturation of Xenopus oocytes (Ohno 2001; Wodarz 2002).

Studies on the formation of cell-cell junctions in MDCK cells show that the Par-aPKC complex is recruited to early cell-cell contacts at initial stages of cell polarization. The complex remains associated with the

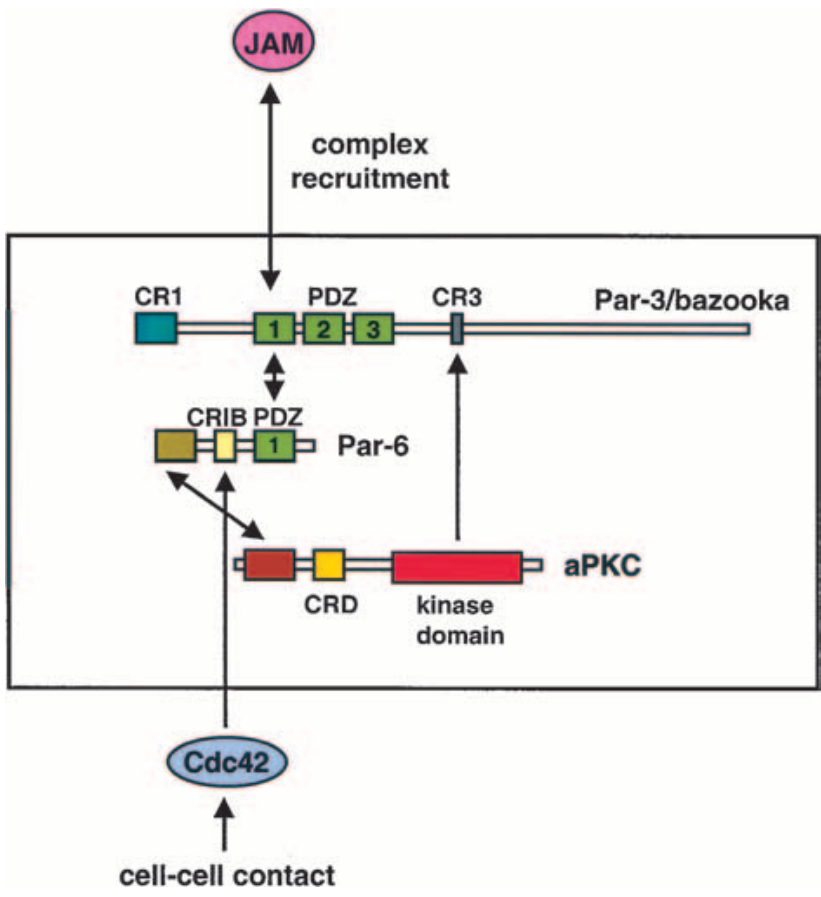

Figure 1. Par-aPKC complex. Control of the Par-aPKC complex by Cdc42. Par-3, Par-6, and a member of the aPKC family form a ternary complex that is evolutionary conserved and plays a role in a large number of functions that involve cell polarity. A model is emerging for the role of this complex in the establishment of epithelial tight junctions in mammals. Cdc42 is activated by initial cell-cell contacts. Cdc42 activates aPKC, thereby loosening the complex and allowing access to the junctional protein JAM, that recruits the complex to nascent tight junctions. The Cdc42-induced conformational changes also could lead to the recruitment of additional signaling components involved in the organization of the actin cytoskeleton and regulation of vesicle trafficking. apical-most zone of the developing cell-cell junctions and is still present at the tight junctions of fully polarized cells. What is the role of Cdc42 in the regulation of this complex? Cdc42 has been shown to activate aPKC in the Par-aPKC complex in a Par-6 dependent manner (Qiu et al. 2000; Yamanaka et al. 2001). The precise role of aPKC activity is not yet clear. One scenario is that phosphorylation of Par-3 by aPKC may change the conformation of the complex, allowing the interaction with junctional proteins that tether the Par-aPKC complex to the plasma membrane (Ohno 2001). A good candidate for such a protein is the recently identified transmembrane protein junctional adhesion molecule (JAM) (Ebnet et al. 2001; Itoh et al. 2001). JAM localizes at new cell contacts at an early stage of tight junction formation, before the recruitment of the Par-aPKC complex (Ebnet et al. 2001; Itoh et al. 2001). Subsequently, the Par-aPKC complex could provide a scaffold for the assembly of additional signaling complexes involved in the organization of the actin cytoskeleton and regulation of vesicular trafficking.

Interestingly, whereas overexpression of kinase-dead aPKC or truncated versions of Par- 6 or JAM interferes with the establishment of new tight junctions, it does not appear to alter the morphology or composition of mature junctions (Joberty et al. 2000; Ebnet et al. 2001; Itoh et al. 2001; Suzuki et al. 2001; Yamanaka et al. 2001). This suggests that the role of the Par-aPKC complex may be restricted to tight junction development rather than maintenance. In contrast, modulation of Cdc42 activity also perturbs the function of established tight junctions, suggesting that Cdc42 utilizes additional signaling elements that are independent of the Par-aPKC complex to control these junctions.

\section{Membrane trafficking in epithelial polarity}

The composition of apical and basolateral surface domains in polarized cells is not only affected by the fence function of tight junctions, but also by membrane trafficking. Polarized membrane trafficking can be divided in direct and indirect routes (Mostov et al. 2000). In the direct mechanism, proteins are sorted in the trans-Golgi network and subsequently directly routed to either the apical or basolateral surface. The indirect mechanism involves endocytosis, usually from the basolateral surface, followed by transcytosis to the opposite surface. Evidence has accumulated in the recent literature for an important role of Rho family GTPases in endocytosis and other aspects of vesicular trafficking (Ellis and Mellor 2000; Ridley 2001b).

Early studies showed that inhibition of Cdc42, but not Rac, induces an accumulation of the basolateral membrane protein gp58 at the apical surface, indicating a depolarization of the basolateral surface (Kroschewski et al. 1999). More recently, Cohen and coworkers (2001) investigated whether this effect of Cdc42 could be attributable to a general disruption of polarized protein traffic or whether it is confined to proteins that are targeted to the basolateral surface. They showed that expression of ei- 
ther constitutively active or dominant negative mutants of $\mathrm{Cdc} 42$ indeed reverses the polarity from basolateral to apical of two different basolateral membrane proteins, vesicular stomatitis virus $\mathrm{G}$ protein and low-density lipoprotein receptor. Modulation of Cdc42 activity, however, does not have any effect on polarized secretion of soluble basolateral proteins or on the targeting of apical membrane or soluble proteins.

Cdc42 is associated with the Golgi apparatus (Erickson et al. 1996; Kroschewski et al. 1999) and expression of either constitutively active or dominant negative mutants of Cdc42 affects Golgi integrity (Kroschewski et al. 1999; Rojas et al. 2001). Therefore, one possible mechanism that could account for the role of Cdc42 in basolateral membrane polarity is that $\mathrm{Cdc} 42$ regulates biosynthetic trafficking. Indeed, recent studies demonstrated that modulation of Cdc42 activity slows down the exit of the basolateral protein, neuronal cell adhesion molecule (NCAM), from the TGN, while stimulating the exit of an apical membrane protein (Musch et al. 2001). These results seem to be in contrast with recent data from Apodaca and coworkers who find that dominant negative Cdc42 can actually somewhat enhance biosynthetic delivery of the polyimmunoglobulin receptor to the basolateral surface (Rojas et al. 2001). Whereas this apparent discrepancy could result from methodological differences, it may also reflect the possibility that different proteins can utilize distinct secretory pathways.

Another potential mechanism that has been proposed to contribute to the role of $\mathrm{Cdc} 42$ in basolateral membrane polarity is that Cdc42 is involved in the fusion of transport vesicles with the surface (Cohen et al. 2001). Indeed, targeting and fusion of basolateral, but not apical, transport vesicles is mediated by the exocyst, a multiprotein complex that localizes to tight junctions (Mostov et al. 2000), and in budding yeast Cdc42 interacts directly with Sec3, a key component of the exocyst (Zhang et al. 2001).

\section{Coordination of apical-basal polarity} with tissue architecture

Tissue morphogenesis and function depend on the coupling of epithelial apical-basolateral polarity to the extracellular environment, that is, the apical domain faces the lumen of the organ and the basal surface contacts the basal lamina. In mammals, interaction with the extracellular matrix is thought to be essential for the proper orientation of the apical-basal axis (Vega-Salas et al. 1987; Wang et al. 1990). A recent study identified Rac as a critical player in the orientation of apical polarity in cysts that are formed by MDCK cells in three-dimensional matrices (O'Brien et al. 2001). Whereas control cells embedded in collagen form cysts in which the apical pole faces the cyst interior, expression of dominant negative Rac inverts this polarity. This reversal of polarity is accompanied by a defect in the assembly of laminin at the cyst surface and proper polarity can be restored by the addition of exogenous laminin. A possible mecha- nism for the role of Rac in laminin assembly is suggested by the observation that dominant negative Rac inhibits the expression of the $\alpha 3$ integrin subunit in the cysts, as the $\alpha 3 \beta 1$ integrin has been shown to be required for laminin assembly (O'Brien et al. 2001). Together, these data suggest a model in which Rac regulates the assembly of extracellular laminin and the assembled laminin in turn provides a spatial signal that is necessary for polarity establishment.

\section{Planar polarity}

In addition to the apical-basal polarity described above, the specialized function of some tissues requires an additional axis of polarity to be established within the epithelium. This is uniform polarity of single cells or multicellular units within the plane of the epithelium, commonly referred to as planar polarity or tissue polarity (Eaton 1997; Mlodzik 1999). Planar polarity in the oviduct, for example, permits the formation of cilia that beat in the same direction, allowing ovum transport towards the uterus (Chailley et al. 1989). Planar polarity in sensory epithelia of the vertebrate inner ear is reflected in the organization of stereocilia (actin-rich finger-like protrusions) in a staircase-like fashion, with the longest steriocilia positioned on one end of the hair cell, followed by stereocilia of decreasing height positioned towards the opposite end. This precisely polarized organization is essential for auditory and vestibular sensory functions (Tilney et al. 1992; Kollmar 1999; Müller and Littlewood-Evans 2001). Other examples include hair outgrowth in Drosophila wings, in which each wing epithelial cell that initially has been polarized along the apicobasal axis orients itself proximally to distally, generating hairs that are all oriented distally, and the uniform orientation of ommatidial clusters of photoreceptors in the compound eye of Drosophila. In the latter case, groups of cells make a coordinated decision (Fig. 2). In particular, studies in Drosophila have shed light on how planar polarity is established and has led to the identification of signaling components that control planar polarity (for review, see Eaton 1997; Shulman et al. 1998; Mlodzik 1999, 2000; Strutt and Strutt 1999; Bray 2000; Adler and Lee 2001; Strutt 2001). Among these components, the Rho GTPases have emerged as key players and will be discussed in detail below.

In contrast to apical-basal polarity, planar polarity is established in the absence of obvious permanent cues, and is therefore thought to be generated by long-range signals. Genetic analyses in Drosophila have led to a model for planar polarity signaling in which cells receive and interpret information from the extracellular environment and then translate this signal into changes in cytoskeletal polarity and transcriptional activation (for reviews, see Eaton 1997; Shulman et al. 1998; Mlodzik 1999; Strutt and Strutt 1999; Bray 2000; Adler and Lee 2001; Strutt 2001). The identity and source of the polarizing signals largely remain to be determined, although it is clear that they are tissue specific. For example, the presumptive signal seems to polarize the wing from the 

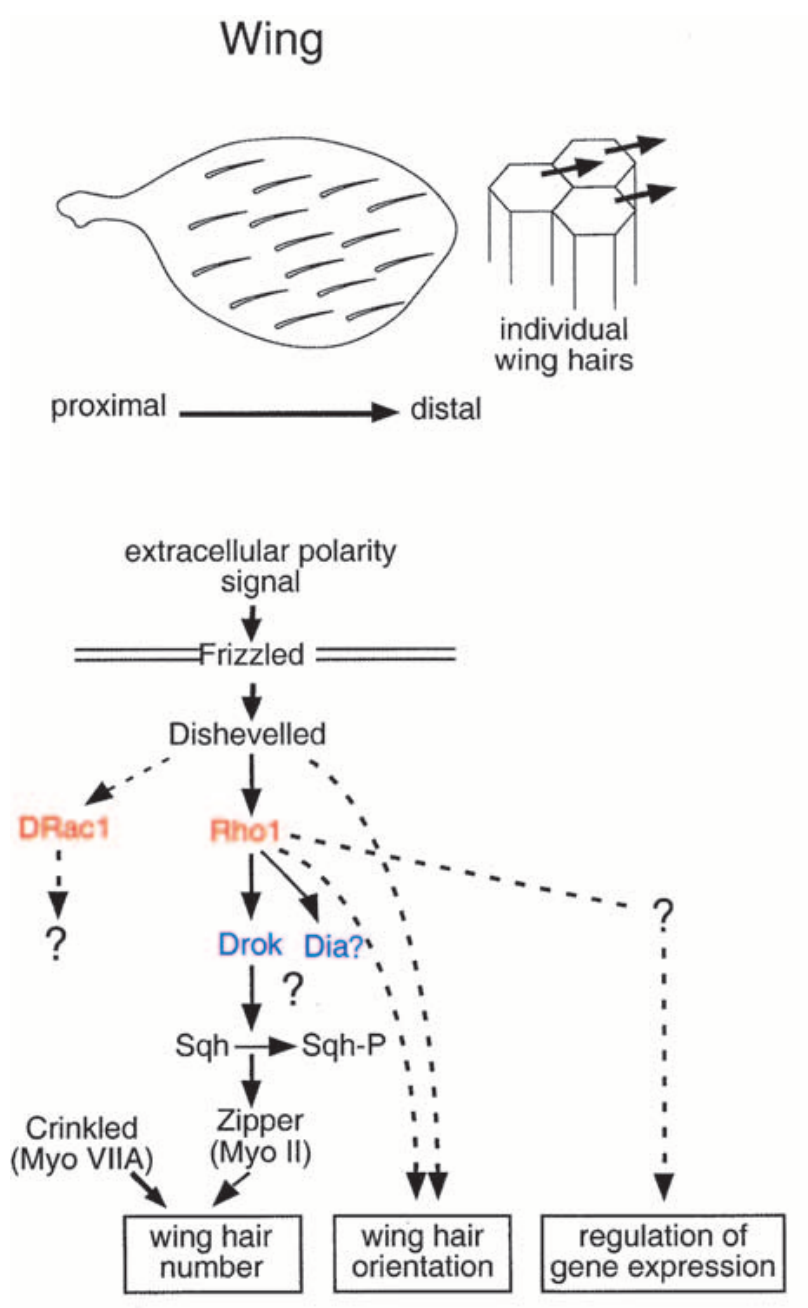
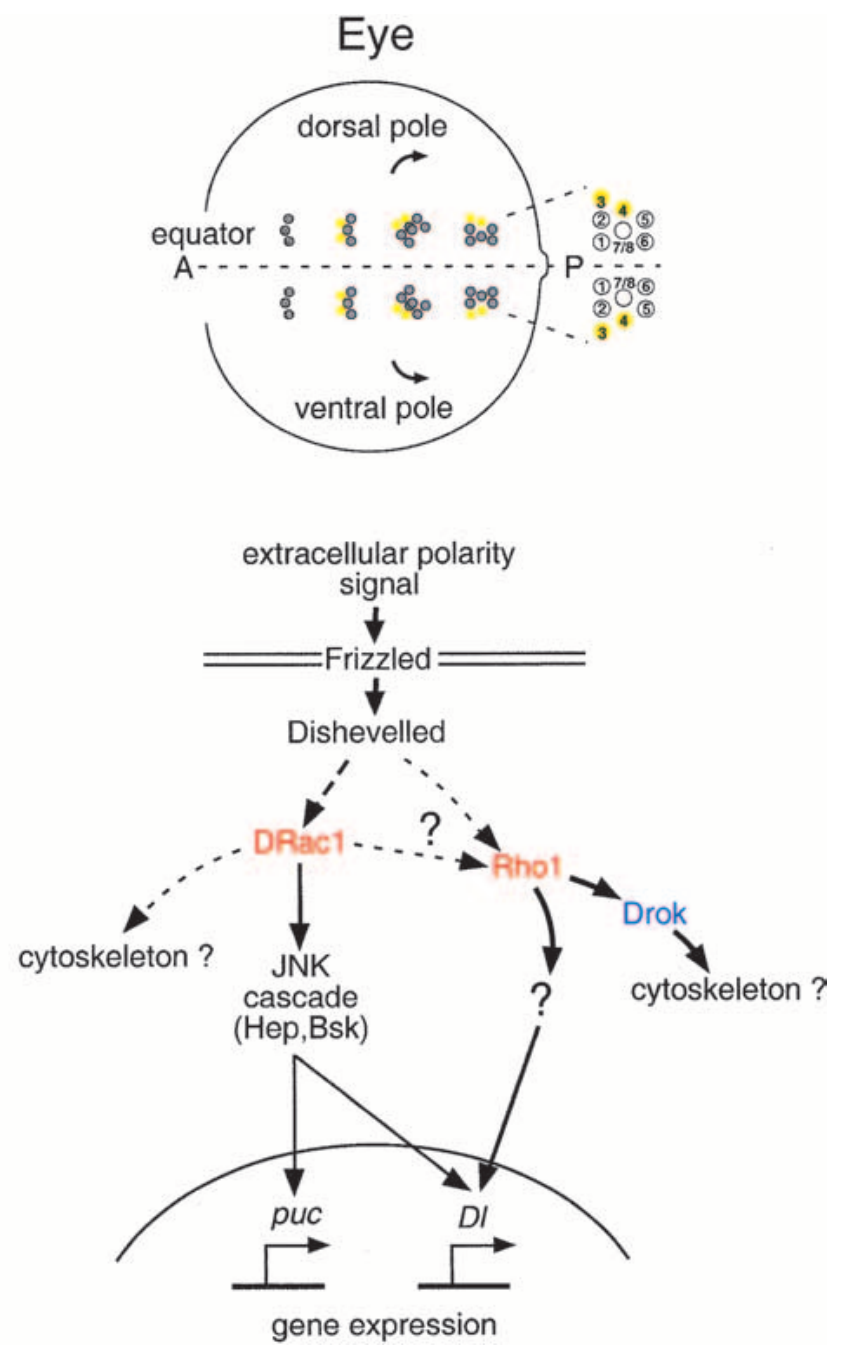

Figure 2. Polarity determination in the Drosophila wing (left) and eye (right). The developing Drosophila wing develops from a monolayer epithelium in which cells are originally polarized only along their apicobasal axis (left). During pupal development, each wing epithelial cell orients itself proximally to distally, generating a single hair at the distal vertex. A model for the wing polarity signaling pathways is depicted below. The sevenpass transmembrane protein, Frizzled, functions as a receptor and signals to Dishevelled. Rho, and likely also Rac, act downstream of Frizzled and Dishevelled. Drok (Drosophila Rho-kinase), Sqh (spaghetti squash or Drosophila nonmuscle myosin regulatory light chain), and Zipper (Drosophila nonmuscle myosin heavy chain) function downstream of Rho and are important in the regulation of the number but not the orientation of F-actin-based prehairs. A separate pathway downstream of Rhol and/or Dishevelled to the cytoskeleton is likely to regulate wing hair orientation. The role of Dia (Diaphanous) in wing planar polarity remains to be defined. Crinkled (Drosophila unconventional myosin VIIA) has opposing effects to that of Zipper in regulating prehair assembly. The pathway downstream of Rho leading to transcriptional activation is less well defined. The Drosophila eye develops from a monolayer epithelium of identical cells (right). Photoreceptor differentiation occurs in a wave from posterior to anterior such that ommatidia at the anterior site are more mature than those located more posteriorly. Photoreceptor cells are sequentially recruited into the nascent ommatidia as differentiation proceeds (the R3/R4 photoreceptor pair is colored yellow, the other photoreceptors are colored gray). The immature clusters initially possess internal-image symmetry, however, as differentiation proceeds, they rotate $90^{\circ}$ and become asymmetric, with the R3/R4 cell closest to the equator taking the R3 fate. Clusters on either side of the equator rotate in opposite directions and thus take an opposite chiral form. A model for the wing polarity signaling pathways is depicted below. Rac1 functions downstream of Frizzled and Dishevelled. Rhol appears to act downstream or in parallel with DRac. Both DRac and Rhol signal to the nucleus, likely through distinct effectors to regulate Dl (Delta) expression. In addition, DRac regulates the expression of Puckered through the activation of the JNK pathway.

proximal edge to the distal edge, whereas the eye is polarized from the equator (the dorsal-ventral midline) to the dorsal and ventral poles (Fig. 2). Components of the signal transduction machinery that interpret the signal have been identified and these appear to be generally conserved amongst different tissues. The seven-pass transmembrane protein Frizzled (Fz) functions as a receptor required for the reception and transmission of polarity signals (Vinson et al. 1989). The next known downstream component of the polarity-signaling pathway is 
the scaffold protein Disheveled (Dsh) that is recruited from the cytoplasm to adherens junctions by Fz (Klingensmith et al. 1994; Theisen et al. 1994; Krasnow et al. 1995). Homologs of both Frizzled and Disheveled have been identified in vertebrates. It is noteworthy that although both $\mathrm{Fz}$ and Dsh also participate in the Wingless (Wg) signal transduction system(s), Wg and planar polarity signaling appear to use different pathways downstream of Dsh in Drosophila (Axelrod et al. 1998; Boutros et al. 1998; but see Habas et al. 2001).

A number of studies suggest that the Rho GTPases are important signaling elements that function downstream of Dsh in the establishment of both eye and wing planar polarity in Drosophila (Eaton et al. 1995, 1996; Strutt et al. 1997; Fanto et al. 2000). Loss- and/or gain-of-function mutants of DRac1 and Rho1 display planar polarity defects in the eye and the wing, similar to those described for $d s h$ mutants. In the wing, cells expressing a dominant negative mutant form of DRac1, DRac1N17, fail to restrict outgrowth to a single site and give rise to multiple wing hairs. This defect is associated with disturbances in the organization of junctional actin as well as with disruption of microtubules associated with the junctional region. Similarly, clones of Rho1 hypomorphic alleles display multiple wing hairs and abnormal wing hair polarity. In contrast to a prominent role for DRacl and Rhol in establishing wing planar polarity, thereby restricting the site at which hairs grow out, DCdc42 functions in the control of localized actin polymerization in the extending hair, rather than in polarity generation itself. Expression of a dominant negative mutant form of DCdc42 abolishes both actin polymerization and hair outgrowth (Eaton et al. 1995, 1996; Strutt et al. 1997). In the eye, interfering with DRacl and Rhol signaling disrupts ommatidial polarity. In a wild type, ommatidial preclusters, when they initially emerge from the furrow, are arranged symmetrically in the anteroposterior axis. Subsequently, they rotate $90^{\circ}$ towards the equator and become asymmetric, with the R3/R4 cell closest to the equator taking on the R3 fate (Fig. 2). Clusters on either site of the equator rotate in opposite directions and take on opposite chiral forms. In eye discs expressing an activated or dominant negative mutant form of DRac1, ommatidial rotation is affected early in development and the R3/R4 pairs often are incorrectly oriented with respect to the neighbors and position in the eye disc. Eye clones carrying hypomorphic Rho1 mutations also are incorrectly rotated relative to the equator and sometimes form inappropriate chiral forms. No role for DCdc42 in the establishment of planar polarity in the eye has been reported (Fanto et al. 2000). Taken together, these studies suggest that DRacl and Rhol, but not Cdc42, play a role in planar polarity generation. One potential caveat is that the above-described Racl studies relied mainly on the use of dominant negative and constitutively active mutant forms of Rac. In more recent studies, an extensive phenotypic analysis of loss-of-function mutations in each of the endogenous Rac genes (including DRac1, DRac2, and Mtl) was performed (Hakeda-Suzuki et al. 2002; Ng et al. 2002). Consistent with the dominant negative and activated DRac mutant analyses, these studies showed that the DRac genes have overlapping functions in the control of dorsal closure, myoblast fusion, and axon growth and guidance. In contrast, however, no defects in planar polarity establishment were observed in clones of cells in the eye and the wing that were triply mutant for null alleles of DRac1, DRac2, and Mtl. These data indicate that DRac proteins are not essential in the generation of planar polarity and that the effects seen with the dominant negative Rac mutant proteins may be attributable to cross-inhibition or cross-activation of other pathways (Hakeda-Suzuki et al. 2002). The latter studies do not, however, exclude a possible involvement of the DRac proteins in signaling pathways that are activated by Fz.

Genetic interaction and rescue experiments have placed DRacl and Rhol downstream of Dsh. For example, in the eye, the gain-of-function phenotype resulting from overexpression $f z$ or $d s h$ are dominantly suppressed by deficiencies that remove DRac1 and DRac2, as well as by a reduction in the gene dose of Rho1, but not by the removal of $D C d c 42$. Furthermore, ectopic expression of DRac1 and Rho1 largely rescues the eye polarity phenotype of a hypomorphic allele of $d s h$ (Strutt et al. 1997; Boutros et al. 1998; Fanto et al. 2000). Similar experiments were performed for Rhol in the wing (Strutt et al. 1997). Taken together, the above studies suggest a role for DRac1 and Rhol downstream of Dsh in the control of planar polarization of both wing hairs and photoreceptor clusters. Consistent with the findings in Drosophila, Habas et al. (2001) recently demonstrated biochemically in mammalian cells that Fz/Dvl (mouse Disheveled) signaling activates Rho and weakly Rac, but not Cdc42. In contrast with the above findings in Drosophila, which do not implicate Wnt signaling in Fz planar cell polarity or Rho GTPase regulation, they demonstrate that the mammalian Wnt-1 and Wnt-11 activate Rho in mammals and in Xenopus. Furthermore, they identified Daam 1 as a novel component, which is essential for Wnt/Fz activation of Rho and for Xenopus gastrulation, a process involving planar polarization (Habas et al. 2001). Daam1 is a member of the family of forminhomology proteins that are thought to act as platforms that direct localized actin polymerization (Wasserman 1998). It is important to note, however, that the sequencing of the Drosophila genome has revealed in addition to Wingless six Wnt homologs in Drosophila (Llimargas and Lawrence 2001). At present, their involvement in Fz planar cell polarity or Rho GTPase regulation remains to be determined.

More recent studies in Drosophila have provided insights into the downstream signaling components of the Rho GTPases in both eye and wing, providing links as to how Fz/Dsh may relay signals to the cytoskeleton and the nucleus. Several lines of evidence indicated that signaling components of the Jun N-terminal kinase (JNK) signaling module play an important role in mediating the effects of $\mathrm{Fz}$ in planar polarity generation (Weber et al. 2000; Ciapponi et al. 2001). Additional studies suggested a role for DRacl upstream of the JNK pathway in 
the eye polarity generation (Fanto et al. 2000) (Fig. 2). A reduction in gene dosage of components of the JNK cascade (such as basket/JNK, hemipterous/JNKK or D-jun) strongly suppresses the ommatidial rotation defect in eyes expressing DRac1V12. Furthermore, expression of DRac1V12 triggers a strong up-regulation of puckered expression. Puckered encodes a MAPK phosphatase whose expression is regulated by the JNK pathway (see below). In addition to puckered, DRac1V12 also up-regulates Delta expression. Delta is the only known transcriptional target of frizzled signaling in the R3 precursors (Fanto et al. 2000). Genetic interaction and rescue experiments have placed Rhol downstream or in parallel to DRac1 (Fanto et al. 2000). However, whereas an activated mutant form of Rhol is able to trigger an increase in Delta expression, it does not up-regulate puckered expression. These data suggest that Rhol-induced signaling to the nucleus is not mediated by JNK and that DRac1 and Rhol utilize different downstream effectors. The identity of Rhol's downstream effector pathway remains to be defined. A potential link between the Rho GTPases and actin cytoskeleton reorganization in the eye remains more elusive, but as discussed below, the Rho-associated kinase (Drok), a Rhol effector, may be a potentially important player in mediating Rhol's effects on the cytoskeleton.

Recent studies by Winter et al. (2001) provide evidence that Drok mediates a branch in the planar polarity pathway involved in ommatidial rotation in the eye and the restriction of hair bundle (trichome) formation to a single site in the wing. Eye clones homozygous for Drok loss-of-function mutation show a similar size as their siblings, however $\sim 50 \%$ of ommatidia exhibit an increase or decrease in photoreceptor numbers when compared to wild-type clones. Of those ommatidia with the correct number of photoreceptors, $\sim 60 \%$ were misrotated. In Drok loss-of-function wing clones multiple hairs are generated, whereas in wild-type wings each cell produces a single, distally oriented hair. These Drok loss-of-function phenotypes resemble those of Rhol mutants. Genetic interaction experiments performed in the wing show that Drok functions downstream of the $\mathrm{Fz} /$ Dsh in regulating the wing hair number. Together with the findings that Drok interacts directly with an activated mutant form of Rhol and that Rhol acts downstream of $\mathrm{Fz} / \mathrm{Dsh}$ in the establishment of eye and wing polarity, these data place Drok as a downstream effector of Rhol in the $\mathrm{Fz}$ signaling pathway. In mammalian cells, the nonmuscle myosin regulatory light chain (MLC) is a critical substrate of Rok (the Drosophila counterpart of Drok) that mediates Rho-stimulated myosin contractility (Kaibuchi et al. 1999a). Consistent with this, the Drosophila ortholog of MLC, Spaghetti squash (Sqh), is an important substrate of Drok. Biochemical and immunostaining experiments demonstrate that Drok modulates Sqh phosphorylation in vivo. Furthermore, the multiple wing hair phenotype as well as lethality of Drok loss-of-function mutants can be suppressed by the presence of a sqhE20E21 transgene. The sqhE20E21 transgene contains mutations in the primary
(Ser 20) and secondary (Thr 20) phosphorylation sites (which are phosphorylated by Drok) changing them to glutamic acid, thereby mimicking phosphorylation on both sites. In addition, the associated myosin heavy chain (myosin II) of Sqh (which is referred to as Zipper in Drosophila) is also required for normal trichome formation in the wing (Winter et al. 2001). Reduction in Zipper activity results in the multihair phenotype. Both Sqh and Zipper have been shown to function downstream of Fz/ Dsh in regulating actin prehair development. Thus in the wing, a linear pathway from $\mathrm{Fz}$ to the regulation of actin structures important for the restriction of the number of F-actin-based prehairs has been established (Fig 2). The precise role of Drok in regulating the process of ommatidial rotation in the eye is less clear. The authors postulate that Drok may function as an effector of Rhol in mediating ommatidial rotation or that loss of Drok may lead to the disruption of the actin cytoskeleton and cellcell contacts that support intracellular signaling essential for ommatidial rotation. Interestingly, the studies by Winter et al. (2001) also show that Crinkled (myosin VIIa) acts in conjunction with the Fz/Dsh/Rhol/Drok/ myosin II pathway in regulating wing hair number. Crinkled has opposing effects to that of myosin II in regulating prehair assembly and a balance between the activities of myosin II and myosin VIIA appears to be important in regulating wing hair number. Drosophila Crinkled is the ortholog of the Usher Syndrome 1B gene that causes deafness in humans and mice deficient in myosin VIIa show defects in the polarity of the stereocilia staircase in the inner ear (Self et al. 1998; Müller and Littlewood-Evans 2001). These findings raise the possibility that a similar Fz/Dsh cytoskeletal pathway regulates a branch of polarity in sensory epithelia of the vertebrate inner ear.

In contrast to Dsh and Rho1, Drok and myosin II are not involved in the determination of the site/orientation of the F-actin based prehairs in the fly wing. These observations suggest that there is a bifurcation of pathways at the level of Rhol and/or Dsh; one pathway is required for the regulation of the number of wing hairs while the other pathway is required for the orientation of these hairs (Winter et al. 2001). The identities of the signaling components important for wing hair orientation remain to be determined. Noteworthy is the observation that mutations in vertebrate diaphanous, another extensively characterized effector of Rho that is a member of the formin-homology family of proteins (Watanabe et al. 1997), lead to the autosomal dominant hearing-loss syndrome DFNA1 (Lynch et al. 1997). In mammalian cells, Dial has been found to work in concert with Rok to induce stress fibers in transfected fibroblasts (Watanabe et al. 1999). In this system, Rok activates the actin-based molecular motor myosin II to exert tension force on actin filaments during stress fiber formation, whereas Dia1 seems to contribute to the determination of nucleation sites for actin filaments. More recent studies in fibroblasts and HeLa cells demonstrate a role for Dial as mediator of RhoA's effects on microtubule stabilization in the leading edge (Ishizaki et al. 2001; Palazzo et al. 
2001a). Based on these observations, it has been speculated that Dial could play a role in regulating the assembly or maintenance of the hair cell cytoskeleton (Müller and Littlewood-Evans 2001). In Drosophila, the Diaphanous protein has been shown to play a role in cytokinesis by organizing actin-mediated events involving membrane invagination (Castrillon and Wasserman 1994; Afshar et al. 2000). It would be interesting to see whether the Drosophila diaphanous gene product acts in concert with Drok in the regulation of the number and/or orientation of the F-actin based prehair in the wing. In light of this, disruption of the microtubule cytoskeleton in the fly wing has been shown to result in wing cells forming multiple hairs without any obvious effects on polarity. It is also important to mention that expression of a dominant negative mutant form of DRacl disrupts the microtubule cytoskeleton in the wing (Eaton et al. 1996). In vertebrates, a molecular pathway linking Rac1 to the growth of microtubule plus ends also is emerging and involves the activation of the serine/threonine kinase Pak, which in turn leads to the phosphorylation and inactivation of stathmin/Op18 (Daub et al. 2001). Stathmin was initially identified as a phosphoprotein highly overexpressed in leukemias, breast, and ovarian cancers and was later found as a protein that binds tubulin dimers, thereby destabilizing microtubules. Two different mechanisms have been suggested by which stathmin may stimulate destabilization of microtubules: Stathmin either sequesters tubulin dimers, which would reduce the concentration of tubulin available for assembly, or it stimulates microtubule plus end catastrophe, the transition from microtubule growth to shortening (Belmont et al. 1996; Belmont and Mitchison 1996; Howell et al. 1999; Larsson et al. 1999; Andersen 2000; Cassimeris 2002). Whether or not a similar pathway exists in Drosophila remains to be seen. Furthermore, the relationship between DRacl and Rhol in regulating planar polarity in the wing remains to be established.

Obviously, further research will be required to determine all the relevant players downstream as well as upstream of the Rho GTPases that are important in the establishment of planar polarity. It is intriguing that several of the downstream components of the Rho GTPases that are important in planar polarity are commonly found in other cell types, such as fibroblasts, where they also regulate nuclear events and cytoskeleton remodeling. Thus, information gained from fibroblast studies may be useful in further unraveling the components involved in planar polarity determination. In addition, the completion of the Drosophila genome sequencing is also likely to advance the identification of the signaling components functioning upstream and downstream of the Rho proteins in establishing eye/wing polarity.

\section{Wound healing}

Directed cell migration is a critical process during many stages of embryonic development. In adult organisms, cell migration plays a crucial role in numerous physiological and disease related processes, including inflam- matory responses, wound healing, and metastasis. Whereas inflammatory responses involve the migration of single cells, such as dendritic cells or leukocytes, wound healing and metastasis also involve migration of a complex epithelium. Data accumulated over several years from both in vivo experiments and tissue culture cells have demonstrated that Rho family members are key regulators of both types of motile behavior (for reviews, see Van Aelst and D'Souza-Schorey 1997; Jones et al. 1998; Keely et al. 1998; Montell 1999; Nabi 1999; Evers et al. 2000; Hall and Nobes 2000; Schmitz et al. 2000; Price and Collard 2001; Ridley 2001a). Here we will focus on the role of the Rho GTPases in the wound healing process and in a closely related process, dorsal closure, which occurs during Drosophila development. Both of these processes involve extensive and directed movements of two epithelial sheets facing each other. The movement and sealing of epithelial sheets can, in general, be subdivided into the following steps: The leading cells are first specified and brought into position. The cells then make a coordinated forward movement by changing their cell shape and/or migrating over a substrate. Subsequently, epithelial cells of the opposing sites merge and fuse (Jacinto et al. 2001).

Two distinct mechanisms have been suggested to account for the movement of epithelial cell sheets during wound healing (Jacinto et al. 2001). In the first process, which is typical for the repair of adult skin wounds, closure of the wound occurs by active protrusion of filopodia and lamellipodia at the edge of the wound, resembling in fact the crawling behavior of free cells (Lauffenburger and Horwitz 1996; Martin 1997). The cells at the migrating leading edge at the wound bore a passageway enabling them to crawl beyond the cut basal lamina and over the provisional matrix and healthy dermis (Martin 1997). In the second process, which is characteristic of wounded embryonic epidermis, repair occurs by a pursestring mechanism that pulls the wound edges together (Martin and Lewis 1992; Martin 1997; Grose and Martin 1999; Kiehart 1999). This involves contraction of actomyosin cables that run around the circumference of the leading epithelia that are linked by adherens junctions. The lamellipodial crawling and purse-string mechanisms are, however, not strictly limited to adult and embryonic tissues, respectively. For instance, epithelial wounds to the adult cornea and gut appear to close through the purse-string mechanism (Heath 1996; Danjo and Gipson 1998). There are also cases where the two types of epithelial motility take place simultaneously or at different stages of the wound healing process. For example, closure of small wounds in intestinal cultured cells involves formation of both lamellipodia and pursestring structures (Bement et al. 1993).

Analogous tissue movements as observed for the repair of embryonic and adult epithelia take place during Drosophila and C. elegans embryogenesis. In C. elegans, the enclosure of the ventral surface of the embryo involves a two-step process in which two functionally distinct groups of hypodermal cells meet and fuse to seal the ventral midline; one is accompanied by filopodia for- 
mation and the other by purse-string contraction (Williams-Masson et al. 1997; Simske and Hardin 2001). During Drosophila embryogenesis, the epidermis undergoes a morphogenetic movement, termed dorsal closure (DC), to establish the dorsal ectoderm (Knust 1997; Goberdhan and Wilson 1998; Noselli 1998; Stronach and Perrimon 1999). Similar to the mechanism described for reepithalization of embryonic skin and some tissue culture wounds, one of the major forces that drives the movement of the epithelial sheets in the Drosophila embryo is the contraction of a cable of actin and myosin running around the circumference of the leading epithelial margin (see below).

Significant progress has recently been made in defining the signaling components mediating wound healing and embryonic tissue movements (for review, see Jacinto et al. 2001) and different members of the Rho-like GTPases have emerged as key players in the purse-string and crawling modes of epithelial motility.

\section{Molecular mechanisms underlying cell movements during wound closure}

In cases where closure of the wound involves lamellipodial crawling, for example in wounds induced in MDCK epithelial cell monolayers, repair of the wound is dependent on Rac1 activity (Fenteany et al. 2000). Cells at the wound margin extend lamellipodia in the direction of the wound, which are followed by a tandem movement of the submarginal cells. Inhibition of Rac activity in the first three rows of cells prevents lamellipodia formation and subsequent wound healing. Interestingly, if Rac1 activity is only blocked in the first row of cells wound healing still occurs, suggesting that cells behind the margin can generate force independently of the first row (Fenteany et al. 2000). Although these cells do not display obvious lamellipodia, they have sites that promote Rac-dependent actin filament assembly, which may provide actin-based force generation in these cells. In contrast to Rac1, inhibition of RhoA or Cdc42 activity in the first three rows does not prevent wound closure, although it occurs in a significantly less regular fashion (Fenteany et al. 2000).

In similar wound healing assays using primary rat embryonic fibroblasts (REFs), the activities of all three GTPases appear to be required for efficient closure of the wound (Nobes and Hall 1999). In this system, Rac1 is required for the protrusion of lamellipodia and forward movement of the cells. Cdc42 activity is required to establish polarity in the migrating cells, whereas basal RhoA activity is required to maintain cell substrate adhesion of the migrating cells (Nobes and Hall 1999). Thus, Rac, Cdc42, and Rho appear to function cooperatively to drive the forward movement of the REF cells.

More recently, the role of members of the Rho GTPases and the underlying mechanisms have been examined in wound-induced astrocyte migration (EtienneManneville and Hall 2001). Scratching a confluent monolayer of astrocytes induces a microtubule-dependent, but actin-independent, polarization of the leading edge cells. This is characterized by the formation of a pseudopodium-like structure, referred to as a protrusion, and by the reorientation of the microtubule-organizing center (MTOC) and the Golgi apparatus in the direction of migration. Detailed analysis of this wounding-induced cell polarization shows that Cdc42 plays a critical role in this process and suggests the following model (Fig. 3A). On localized activation of integrins at the front of the cells, Cdc42 becomes activated, which leads to the recruitment of the above-described Par6/PKC $\zeta$ complex to the plasma membrane at the leading edge, and to the activation of PKC $\zeta$. Localized activation of $\mathrm{PKC} \zeta$ may then act on the motor protein dynein to establish cell polarity (Etienne-Manneville and Hall 2001). Consistent with this model, Cdc42 also mediates MTOC reorientation in a dynein-dependent manner in wounded NIH 3T3 fibroblast cells (Palazzo et al. 2001b). In the astrocyte model, Cdc42 is in addition required for the formation of protrusions, although only at early stages after wounding. In contrast, Rac is not required for the establishment of cell polarity, but is essential for the development and the maintenance of protrusions during migration. A potential mechanism for this function of Rac is that Rac, via $\mathrm{PAK}$, could phosphorylate and inactivate stathmin, thereby promoting microtubule elongation (Andersen 2000; Daub et al. 2001; Cassimeris 2002). Interestingly, Rac has been shown to be activated by microtubule polymerization (Waterman-Storer et al. 1999). This suggests the possibility of a positive feedback loop that is localized to the leading edge of the moving cell and coordinates microtubule growth with actin polymerization: Rac, via inactivation of stathmin, stimulates microtubule elongation, which in turn enhances Rac activity. Presently, it remains unclear as to whether Rac is activated via Cdc42 or directly by an integrin-based mechanism (Fig. 3A).

In situations where wound healing occurs by means of a contractile purse string, the function of RhoA appears to be essential. Studies in embryonic wound healing models, for example wounds in the embryonic chick wing bud, have shown that the assembly and the contraction of actin cables is dependent on RhoA activity (Brock et al. 1996). Loading of wound edge epidermal cells with C3 transferase prevents assembly of an actin cable and causes a failure of healing. In contrast, expression of a dominant negative mutant of Rac does not interfere with the assembly of an actin cable or with healing. A possible candidate for mediating Rho's effect on the actin filament cable is Rok, as this molecule is a key Rho effector in the regulation of actomyosin contractility. Furthermore, a role for Rok in wound-induced migration has been demonstrated in rat hepatic stellate cells (Tangkijvanich et al. 2001). In studies using mouse corneas with central epithelial debridement wounds, which heal by the contractile purse-string mechanism, it was noted that the actin filament cable is anchored by E-cadherin-mediated adherens junctions at the leading edge, thereby joining the cells to form the purse-string. In light of the role of Rho in the establishment of adherens junctions, as discussed above, these findings sug- 


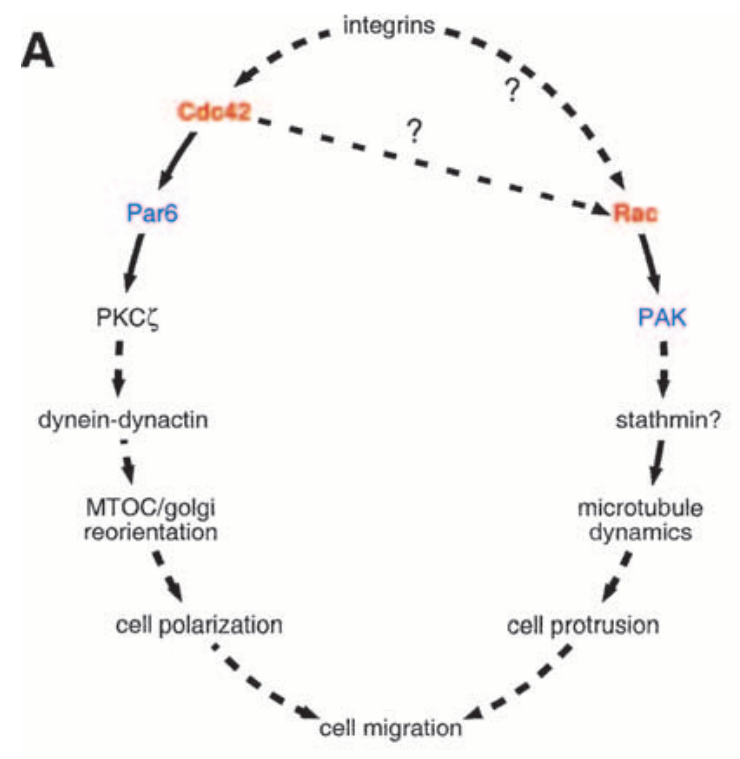

B
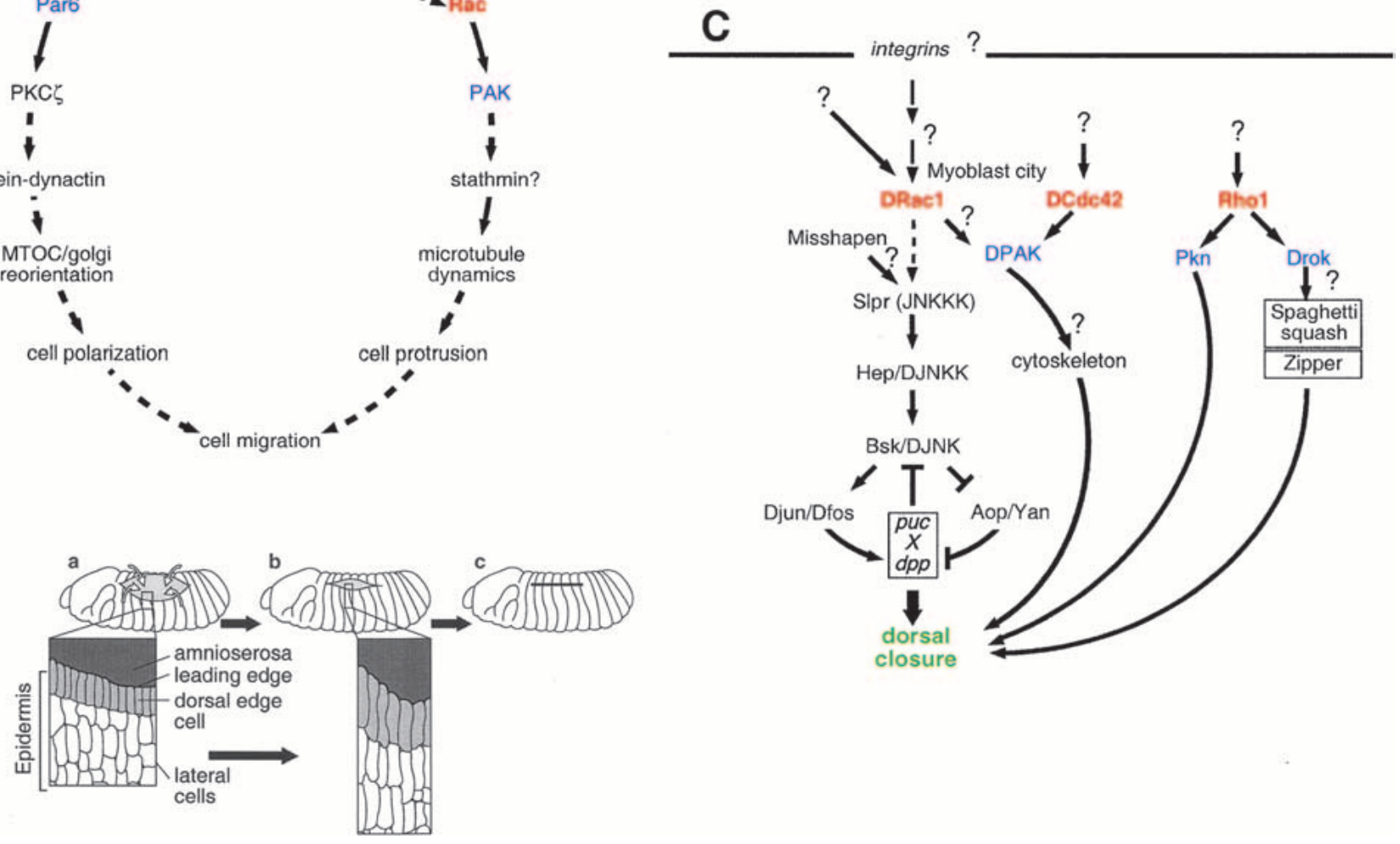

Figure 3. (A) Model for signal transduction pathways underlying wound-induced astrocyte migration. On integrin engagement, Cdc42 becomes activated causing the recruitment of Par6 and $\mathrm{PKC} \zeta$ to the leading edge plasma membrane, followed by the activation of PKC $\zeta$. Activated PKC $\zeta$ then leads to the recruitment and/or activation of dynein, contributing to the reorientation of the MTOC toward the front of the cell. Rac activation (through integrins and/or Cdc42) is essential for the microtubule-dependent formation of protrusions. One potential mechanism by which Rac could exert this effect involves activation of its effector PAK, which in turn phosphorylates and inhibits stathmin. (B) Dorsal closure. Dorsal closure can be divided into three major steps: initiation (a), spreading (b), and suture (c). Initially, cells at the leading edge (LE) of the dorsal epidermis elongate dorsally. This is associated with the accumulation of actin and nonmuscle myosin beneath the dorsal-most cell membranes, which form the 'leading edge' of the epithelial sheet. The initial elongation of the LE cells is followed by a spreading phase. The more lateral ectodermal cells undergo progressive dorsal-ventral elongation and promote spreading of the more lateral sheets over the amnioserosa. Recent studies indicate also that the amnioserosa may provide some contractile forces (Kiehart et al. 2000). These dramatic shape changes eventually cause the entire dorsolateral epithelium to cover the region that was previously occupied by the amnioserosa. During the last phase of DC, ectodermal sheets meet at the dorsal midline and adhere to one another and suture. $(C)$ Schematic representation of the signaling pathways mediated by the Rho GTPases that direct the DC process. Activation of DRac and DCdc42 reorganize the LE actin cytoskeleton, leading to the activation of the JNK-MAPK pathway in the LE. An important outcome of JNK activation is the induction of $d p p$ (TGF- $\beta$ homolog). The latter controls morphogenesis of the more lateral ectoderm cells. Restriction of JNK activation to the LE is in part caused by the repressor function of the phosphatase Puckered (Puc). Rhol activity is required for the integrity of the LE cytoskeleton, however, its effects on the cytoskeletal assembly are restricted to cells flanking the segment borders. Potential mediators of Rhol are Drok and PKN. In contrast to DRacl and DCdc42, Rhol is not involved in JNK activation and induction of $d p p$ expression.

gest that Rho may control this type of wound healing both by regulating the contractile properties of the pursestring and by anchoring it (Danjo and Gipson 1998).

Dorsal closure in Drosophila as a model system for wound repair

Additional insights into the molecular mechanisms operating during wound repair come from studies of analo- gous morphogenetic movements that occur in genetically tractable embryos, such as DC in Drosophila. In late stages of development, the dorsal trunk region of the Drosophila embryo remains without ectoderm and is instead covered by a transient epithelial structure, the amnioserosa. During the process of DC, the dorsal-most, or 'leading edge' (LE) cells of the lateral epidermis elongate along the dorsal-ventral axis, which is associated with the accumulation of actin and nonmuscle myosin be- 
neath the dorsal-most cell membranes. It has been proposed that the accumulation of F-actin and myosin at the leading edge forms the actomyosin contractile apparatus driving the elongation of the LE cells. Subsequently, cells located more laterally gradually lose their polygonal shape and elongate as a result of the contractions at the LE, thereby shifting the whole epidermis dorsally toward the midline. Finally, the leading edges of both sides meet at the dorsal midline and fuse (Fig. 3B; for reviews, see Knust 1997; Goberdhan and Wilson 1998; Noselli 1998; Stronach and Perrimon 1999).

Genetic analyses have revealed the involvement of all three Rho GTPases (DRac1, DCdc42, Rhol) in the DC process. Expression of dominant negative mutant versions of any of the three GTPases result in DC defects (Harden et al. 1995, 1999). Moreover, loss-of-function mutations have been generated in the Drosophila DCdc42 and Rho1 genes, and both these mutant embryos show DC defects (Magie et al. 1999; Genova et al. 2000). It is noteworthy that expression of constitutively active forms of the three GTPases also causes DC defects, suggesting that cycling between the GTP- and GDP-bound states of the GTPases and/or correct spatial activation are required (Harden et al. 1999). Alternatively, as already mentioned above, one can not exclude the possibility that the dominant negative mutant form of a Rho GTPase has an inhibitory effect and a constitutively active mutant form produces a gain-of-function phenotype.

Although interference with either DRac1, DCdc42, or Rhol activity results in cuticles with dorsal holes, the three GTPases appear to play distinct roles in the DC process. DRacl is required for the formation and/or maintenance of the cytoskeleton all along the LE, as interfering with DRacl activity causes severe disruption of the LE cytoskeleton (Harden et al. 1995, 1999). Rhol is required for the integrity of the LE cytoskeleton, especially in cells flanking the segment borders (Barrett et al. 1997; Harden et al. 1999). Expression of a dominant negative mutant of Rho1 leads to a loss of LE components and a loss of anterior-posterior contraction in cells flanking each segment border. DCdc42 has also a role in the initial assembly and/or maintenance of the LE cytoskeleton, although to a much lesser extent than DRac. Furthermore, DCdc42 appears to be involved in regulating the levels of DPAK, a downstream effector of DCdc42 and DRac, at the LE and the mechanics of the DC process (Harden et al. 1999; Ricos et al. 1999). Taken together, the observations made on the Drosophila DC process indicate that coordinate actions of the Rho GTPases (which may take place in different subpopulations of LE cells) are essential for DC.

The exact mechanism as to how DRac and DCdc42 affect the actin cytoskeleton in the leading edge is not yet clear. However, a few studies suggest a role for the Drosophila JNK pathway, which is activated by DRac1 and DCdc42 (see below) in the regulation of cell shape changes and actin reorganization. JNK pathway mutants seem to fail in accumulating the proper cytoskeletal network in the LE cells required to fully elongate dorsally
(Hou et al. 1997; Harden et al. 1999; Ricos et al. 1999). Furthermore, in a screen for JNK responsive genes in the Drosophila embryo, the gene chickadee, which encodes for a Drosophila profilin, was identified as one of the up-regulated genes. Chic-deficient embryos fail to execute the JNK-mediated cytoskeletal rearrangements during dorsal closure (Jasper et al. 2001). In addition, Otto et al. (2000) recently identified a novel DJNK-interacting protein, p150-Spir, which belongs to the WiscottAldrich syndrome protein (WASP) homology domain 2 family of proteins, which have been shown previously to be involved in actin organization.

As alluded to above, DRac1 and DCdc42 also function in the LE cells to promote the activation of components of the MAPK pathway (Fig. 3C) (for review, see Stronach and Perrimon 1999). These include DJNKK (Hemipterous; Hep) (Glise et al. 1995), which subsequently activates DJNK (Basket; Bsk) (Sluss et al. 1996; Glise and Noselli 1997). In addition, the Ste20-related kinase, Misshapen (Msn) has been shown to function upstream of Hep and Bsk to stimulate dorsal closure (Su et al. 1998), and more recently, Stronach and Perrimon (2002) have identified Slipper (Slpr) as the upstream activator of DJNKK required for dorsal closure. A model is proposed that Msn, Slpr, and DRacl participate in a ternary signaling complex to stimulate DJNK signal transduction (Stronach and Perrimon 2002). It is well established that DJNK regulates the activity of several transcription factors. In particular, DJNK phosphorylates and activates Djun, which dimerizes with DFos to form a typical AP-1 complex (Hou et al. 1997; Kockel et al. 1997; RiesgoEscovar and Hafen 1997a,b; Zeitlinger et al. 1997; Stronach and Perrimon 1999). DJNK also phosphorylates and inactivates the ETS-domain repressor Anterior open (Aop) (Riesgo-Escovar and Hafen 1997b). The concomitant assembly of AP-1 complexes and inactivation of Aop then leads to the transcriptional up-regulation of $d p p$ and puc expression in the LE cells. Puc encodes a MAPK phosphatase which down-regulates DJNK/Bsk activity and thus negatively feeds back into the JNK signaling pathway (Martin-Blanco et al. 1998). Dpp is a secreted signaling molecule of the transforming growth factor $\beta$ (TGF- $\beta$ ) family (Padgett et al. 1987). Two Dpp receptors, Thick vein (Tkv) and Punt (Put), have been identified in flies, as well as a number of components acting downstream of these receptors, including Mad, Medea, and the Zinc finger protein Schnurri (Brummel et al. 1994; Nellen et al. 1994; Penton et al. 1994; Arora et al. 1995; Grieder et al. 1995; Letsou et al. 1995; Ruberte et al. 1995; Stronach and Perrimon 1999). Loss-of-function mutations in hep, bsk, DIun, and DFos all lead to severe DC defects that are characterized by a complete failure of the entire lateral ectoderm, including the LE cells, to elongate dorsally. This indicates that activation of the JNK pathway is required for the elongation of all cells of the lateral ectoderm. On the contrary, in loss-offunction mutants of $t \mathrm{kv}$, put, and schnurri, the cells of the LE still elongate, while those of the lateral ectoderm do not, indicating that the Dpp signal emanating from the LE cells is necessary for the elongation of the adja- 
cent ectodermal cells, but not for the elongation of the LE cells themselves (Knust 1997). Although the JNK signaling pathway has not been directly implicated in wound repair in mammalian systems, it should be noted that a pivotal role for TGF- $\beta$ in the tissue-repair process is well documented (Grande 1997; Martin 1997; O'Kane and Ferguson 1997; Massague 1999; Ashcroft and Roberts 2000).

In contrast to DRac1 and DCdc42, Rho1 does not appear to stimulate activation of the DINK pathway. While Rho1 loss-of-function mutant embryos showed defects in LE stretching, wild type levels of $d p p$ expression were observed in the LE cells (Lu and Settleman 1999a,b). The effects of Rhol on DC appear, at least partially, to be mediated by PKN kinase (Lu and Settleman 1999a), a Rhol effector that is conserved in mammals and has been shown to mediate insulin-induced reorganization of the actin cytoskeleton (Dong et al. 2000). As observed for Rho1, PKN is required for DC, but is dispensable for Dpp expression (Lu and Settleman 1999a). Indirect evidence also implicates Drok1, the Drosophila homolog of vertebrate Rho-kinase, in DC. In particular, Zipper (myosin II), which as described above functions downstream of Drok in the generation of wing planar polarity, is required for DC (Young et al. 1993). Furthermore a Zipper$R$ ho1 genetic interaction has recently been reported during Drosophila morphogenesis (Halsell et al. 2000). Thus, it is likely that Drok participates in DC as well. Given that Rok is a key Rho effector that mediates actomyosin contractility in mammalian cells, it is possible that a major role of Rhol in the DC process is to regulate contractility during purse-string action.

The nature of the upstream signaling components of the Rho GTPases in DC is less well-defined (Settleman 2001). One likely candidate is encoded by the gene called myoblast city $(\mathrm{mbc})$, which was initially identified in a screen for dominant suppressors of a Rac-induced rougheye phenotype (Nolan et al. 1998). Mbc mutant embryos exhibit a DC phenotype (Erickson et al. 1997; Nolan et al. 1998). Homologs of $m b c$ have been identified both in C. elegans (called ced5) and in mammals (called DOCK180) (Hasegawa et al. 1996; Wu and Horvitz 1998). In mammals, DOCK180 has been shown to trigger the activation of Rac1, potentially through interaction with a specific GEF that activates Rac, given that as yet no in vitro GEF activity has been demonstrated for DOCK180 itself (Kiyokawa et al. 1998; Nolan et al. 1998). Furthermore, DOCK180, CrkII and Rac1, along with another adaptor protein p130Cas, have been linked to cell migration downstream of integrin activation (Klemke et al. 1998; Cheresh et al. 1999). More recently, an additional Dock180-interacting protein called ELMO-1 has been found that functions together with CrkII and Dock180 to activate Rac1, which in turn is required for cell migration (Gumienny et al. 2001). A homolog of ELMO-1, designated Ced12, has been identified in C. elegans and has been shown to be a component of the Ced-2 (CrkII)/ced5 (Dock180)/ced-10 (Rac) pathway that is involved in the regulation of cell migration in C. elegans (Conradt 2001; Gumienny et al. 2001; Wu et al. 2001; Zhou et al. 2001). Future studies will undoubtedly examine the potential function of these proteins in DC and wound repair. It is noteworthy in this respect that both in the DC and wound healing processes integrins have proven to play a major role. (Harden et al. 1996; Lotz et al. 1997, 2000; Stark et al. 1997; Goldfinger et al. 1999; Mercurio et al. 2001). For example, mutations in the Drosophila integrin receptor $\beta$-subunit (myospheroid) and in the $\alpha 3$ subunit (scab) of the integrin receptor lead to a DC defect (MacKrell et al. 1988; Stark et al. 1997).

\section{Molecular mechanisms underlying sealing of epithelial sheets}

During the final steps of enclosing a natural occurring hole or wound, it is critical that cell movement stops and that cells of the two opposing epithelial faces sense each other and adhere tightly to their opposite numbers to form a permanent seam (Abercrombie 1967; MartinBlanco and Knust 2001). Insights as to how epithelial cells correctly adhere and subsequently fuse initially came from analyses of the late stages of ventral enclosure in C. elegans (Williams-Masson et al. 1997; Raich et al. 1999). These analyses revealed that when the two epithelial sheets move towards each other, the epidermal cells extend filopodia and that on contact of two opposing filopodia, adherens junction proteins cluster at the tips. Subsequently, these initial contact sites evolve into mature adherens junctions.

An almost identical actin-based protrusion-mediated mechanism has been demonstrated to occur during the final zippering stages of Drosophila DC. Jacinto et al. (2000) demonstrated that the induction of filopodia on opposing epithelial faces during the final stages of DC are critical in the correct matching of the opposing cells and in the adhesion of the epithelial fronts along the fusion seam. The induction of filopodia appears to require Cdc42 activity, as expression of a dominant negative mutant form of DCdc 42 interferes with this process, resulting in incorrect fusing of opposing cells. Interestingly, disruption of the DJNK pathway in the LE cells also blocks filopodia formation mediated by DCdc42, suggesting that the DCdc42-triggered actin assembly in these cells requires JNK activation (Jacinto et al. 2000).

Recently, a similar mechanism of filopodia extension has been reported to take place during junction formation in epithelial cells in culture (Adams et al. 1998; Vasioukhin et al. 2000; Vasioukhin and Fuchs 2001). Exposure of these cells to calcium triggers the formation of filopodia, which on contact slide along each other and penetrate the membrane of the opposing cell. As is the case during ventral closure, adherens junction proteins accumulate at the embedded tips of filopodia, generating a two-rowed zipper of embedded puncta. After the two cell surfaces are pulled together, they are clamped by desmosomes. In addition to E-cadherin and catenins, the adherens junctions include also proteins such as VASP, Mena, vinculin, and zyxin (Vasioukhin et al. 2000). It has been postulated that Vasp and Mena are involved in directed actin polymerization at stabilized puncta, as such generating the necessary force to push the two rows of 
puncta together into a single row and further seal the membranes into an epithelial sheet (Vasioukhin and Fuchs 2001). Given the recent finding that Cdc42 triggers filopodia formation by promoting the formation of an IRSp53/Mena complex (Krugmann et al. 2001), it is tempting to speculate that $\mathrm{Cdc} 42$ also has a role in adhesion junction formation in skin epithelial cells.

\section{Epithelial-mesenchymal transitions}

During epithelial-mesenchymal transitions (EMT), epithelial cells lose many of their distinctive epithelial features and take on a more mesenchymal fibroblastic phenotype. In particular, epithelial cells lose their polarized morphology, display less organized cell-cell junctions, and become more migratory. EMTs occur at many instances during embryogenesis, such as emigration of neural crest cells from the neural tube, gastrulation movements in many species, and the formation of cardiac valves (Duband et al. 1995; Hay 1995; Viebahn 1995; Markwald et al. 1996; Selleck and Bronner-Fraser 2000; Pla et al. 2001). It is important to note that EMT and loss of epithelial polarity also are recapitulated during later stages of tumor development (Hay 1995; Thiery and Chopin 1999|. Numerous pathways have been described that control EMT transition in a variety of cell models (for reviews, see Hay 1995; Boyer et al. 2000; Savagner 2001). We will focus here on the role of the Rho proteins in EMT in some of these model systems.

EMT transitions can be initiated by numerous extracellular signals, including scatter factor/hepatocyte growth factor (SF/HGF) (Stoker et al. 1987; Stoker 1989; Rosen et al. 1990; Gherardi and Stoker 1991; Vande Woude et al. 1997) and members of the TGF- $\beta$ family (McLeod et al. 1990; Cui et al. 1996; Oft et al. 1998; Portella et al. 1998). Scattering of MDCK kidney epithelial cells induced by HGF has emerged as a powerful paradigm to study the role of Rho GTPases in EMT. HGF induces multiple effects that promote MDCK cell scattering. These include the induction of actin cytoskeletal rearrangements that contribute to the centrifugal spreading, followed by the disruption of cell-cell junctions, and finally cell scattering. HGF triggers the activation of Cdc42 and Rac, accompanied by the induction of filopodia and lamellipodia (Royal et al. 2000; Zondag et al. 2000), and introduction of dominant negative versions of these GTPases interfered with the formation of filopodia and lamellipodia respectively and inhibits scattering (Ridley et al. 1995; Royal et al. 2000). HGF also stimulates Rho activity (Zondag et al. 2000). The precise role of Rho in HGF-stimulated scattering remains controversial however. In one study using MDCK cells, inhibition of Rho was shown to promote scattering and introduction of constitutively active Rho interfered with this process (Ridley et al. 1995), whereas in another study using keratinocytes, inhibition of Rho interferes with HGFinduced scattering (Takaishi et al. 1994). Cell type specificity and the extent of Rho inhibition may both contribute to this discrepancy. The potential roles of Rho GTPases in the disruption of cell-cell junctions by HGF also need to be further clarified. In MDCK cells, both inhibition and constitutive activation of Rac interfere with HGF-induced breakdown of adherens junctions (Hordijk et al. 1997; Potempa and Ridley 1998). Similar results were obtained in the case of Ras-induced disruption of adherens junctions (see below).

Members of the Rho GTPases also have been found to play a role in TGF- $\beta$ - and integrin-induced cell scattering. Although TGF- $\beta$ is regarded as a major tumor suppressor during early tumor development through inhibition of cell cycle progression and cell growth, TGF- $\beta$ can also act as a promoter of tumor progression by stimulating the EMT process. In fact, many late stage tumors are resistant to growth inhibition by TGF- $\beta$ and even secrete TGF- $\beta$. Ras-transformed mammary epithelial cells for instance can undergo TGF- $\beta$-induced EMT, maintained via a TGF- $\beta$ autocrine loop (McLeod et al. 1990; Cui et al. 1996; Oft et al. 1998; Portella et al. 1998). Treatment of epithelial cells with TGF- $\beta$ results in disruption of cellcell adhesions and a change in cell morphology to a spindle shape, accompanied by the loss of E-cadherin junctional localization and the acquisition of stress fibers (Piek et al. 1999; Bhowmick et al. 2001). Moses and colleagues provided evidence that one of the mechanisms by which TGF- $\beta$ mediates EMT involves a Rho/ Rok-dependent signaling pathway. TGF- $\beta$ triggers a rapid activation of RhoA in several nontransformed epithelial cell lines. Furthermore, expression of a dominant negative mutant form of RhoA or its effector Rok inhibits TGF- $\beta$-mediated EMT (Bhowmick et al. 2001).

A large number of studies have highlighted the importance of cross talk between integrins and cadherins in the regulation of cell scattering/EMT (for review, see Pignatelli 1998). In one model system, expression of $\beta 1$ integrins in $\beta 1$-deficient epithelial cells has been shown to induce the disruption of intercellular adhesions, followed by cell scattering. This is accompanied by a decrease of cadherin and $\alpha$-catenin protein levels and the activation of the RhoGTPases, RhoA and Rac, but not Cdc42 (Gimond et al. 1999). Expression of dominant negative mutant forms of Rac and RhoA prevents these $\beta 1$-integrin-induced changes, suggesting that these GTPases contribute to the loss of cell-cell adhesion. Although no apparent activation of $\mathrm{Cdc} 42$ by $\beta 1$-integrins can be detected, basal levels of Cdc42 seem to be required for scattering, as expression of a dominant negative mutant form of Cdc42 also inhibits cell scattering and partially restores cell-cell adhesion /Gimond et al. 1999).

Taken together, the above data support a critical role for Rho GTPases in mediating EMT (cell scattering) triggered by different extracellular factors. A similar transition from epithelial to mesenchymal phenotype is observed in oncogenic Ras-transformed epithelial cells. These cells show loss of E-cadherin-mediated cell-cell adhesion, and an increase in focal adhesions and stress fibers, as well invasiveness (Behrens et al. 1989; Birchmeier et al. 1991; Vleminckx et al. 1991). Several studies have implicated the Rac and Rho GTPases in mediating this Ras-induced morphological transformation (Hordijk 
et al. 1997; Zhong et al. 1997; Quinlan 1999; Braga et al. 2000; Zondag et al. 2000). Interestingly, whereas an increase in Rac activity is required for HGF/SF and $\beta 1$ integrin-triggered EMT, different studies show opposing data for the activation status and function of Rac in Ras transformed epithelial cells. In keratinocytes, inhibition of Rac prevents disassembly of adherens junctions caused by oncogenic Ras (Braga et al. 2000). Moreover, as mentioned above, in these cells, sustained expression of an activated form of Rac is sufficient to disassemble cadherin-mediated contacts (Braga et al. 2000). These data are consistent with the observation that activated Rac promotes cell-cell adhesion breakdown in T47D mammary carcinoma cells (Keely et al. 1997). In addition, Rac activation has been shown to contribute to the Ras-dependent perturbation of cell-cell contacts in breast cancer cell lines (Quinlan 1999). In MDCK cells, however, the opposite is observed. In these cells, expression of Tiam1, a Rac-specific GEF, or activated Rac restores cadherin-mediated cell adhesion and concomitantly inhibits the Ras-induced invasive phenotype (Hordijk et al. 1997). Concordant with these findings, Collard and colleagues found that sustained signaling by oncogenic Ras downregulates Rac activity through the MAPK signaling pathway in MDCK cells (Sander et al. 1999; Zondag et al. 2000). A number of factors may reconcile the paradoxical observations made for Rac's involvement in transformation-induced EMT. The nature of the extracellular matrix on which the cells are plated is likely to contribute to the differences. Indeed, Tiam-expressing RasV12transformed MDCK cells showed a fibroblast-like migratory phenotype when plated on collagen, but an epithelial phenotype when plated on laminin or fibronectin (Sander et al. 1998). Differences in cell type and/or the levels and duration of expression of Ras and Rac proteins also may be important.

Studies performed in Ras transformed MCF10A cells illustrate that activation of RhoA also contributes to the fibroblastic phenotype of these cells (Zhong et al. 1997). A possible mechanism for this is that increased contractility that is stimulated by RhoA promotes the formation of stress fibers and focal adhesions and contributes to the disruption of adherens junctions. This RhoA-induced increase in contractility, however, is not sufficient for the disruption of adherens junctions, because inhibition of Rho only partially restores the epithelial phenotype of Ras transformed cells and expression of an activated mutant form of RhoA does not mimick the Ras transformed phenotype (Zhong et al. 1997).

Once epithelial cells dissociate from each other and, at least partially, from the extracellular matrix (ECM), they become motile. Cell migration can be divided into different steps, each of which appears to be differentially regulated by a specific subfamily of Rho GTPases. A migrating cell senses the extracellular environment, including extracellular matrix and soluble or immobilized cytokines, and this information can be used to establish the directionality of movement. Increasing evidence suggests that $\mathrm{Cdc} 42$, which regulates filopodia formation, is required for the interpretation of extracellular cues
(Zheng et al. 1996; Gomez et al. 2001). In a second step, Rac-dependent lamellipodia formation is induced at the leading edge of the cell and subsequently these extensions are stabilized through the formation of new adhesion sites to the ECM. A final step consists of the forward movement of the cell body proper, followed by the detachment and retraction of the tail. Rho is important in the generation of contractile force and moving the body and the tail of the cell beyond the leading edge. Rho proteins are thought to accomplish these functions largely by their effects on the actin cytoskeleton. Multiple downstream effectors of Rac, Cdc42, and RhoA mediating the reorganization of the actin cytoskeleton have been identified over the past several years. The most prominent effectors involved in the control of actin dynamics are depicted in Figure 4. This work has been extensively covered in a number of recent reviews (Van Aelst and D'Souza-Schorey 1997; Keely et al. 1998; Machesky and Gould 1999; Machesky and Insall 1999; Nabi 1999; Ridley et al. 1999; Sander and Collard 1999; Christopher and Guan 2000; Evers et al. 2000; Hall and Nobes 2000; Schmitz et al. 2000; Condeelis 2001; de Curtis 2001; Price and Collard 2001; Ridley 2001a). In addition to their effects on the actin cytoskeleton, the Rho proteins have subsequently been found to regulate other processes that are relevant to cell migration. These include microtubule dynamics (Gundersen et al. 1998; Hollenbeck 2001; Wittmann and Waterman-Storer 2001), vesicle trafficking (Ellis and Mellor 2000; Ridley $2001 \mathrm{~b})$, and control of extracellular matrix degrading enzymes (Bourguignon 2001).

\section{Concluding remarks}

The observations discussed in this review highlight essential functions of Rho family members in multiple aspects of the establishment and maintenance of epithelial cell polarity and cell morphology. In particular, studies in tissue culture combined with genetic analysis in model organisms such as Drosophila have greatly helped to elucidate Rho-regulated signaling mechanisms that regulate epithelial morphogenesis.

The Rho proteins have emerged as key players in mediating the effects of extracellular signals (including secreted factors, cell surface-associated ligands, and adhesion molecules) to the downstream cellular machinery that controls the organization of the actin cytoskeleton, determining cell shape, adhesion, contractility, and movement. A large number of effector molecules of Rho GTPases have been identified that link them to the cytoskeleton. Much less is known about the signaling mechanisms that translate the extracellular cues into spatio-temporal regulation of the Rho GTPases. It is likely, however, that the concerted action of GEFs and GAPs is critical for the precisely timed and strictly localized activation of the Rho GTPases (Symons and Settleman 2000; Gulli and Peter 2001). This tight control may explain how the individual Rho GTPases can mediate multiple temporally and spatially distinct processes. Good examples of the coordinate action of two or 

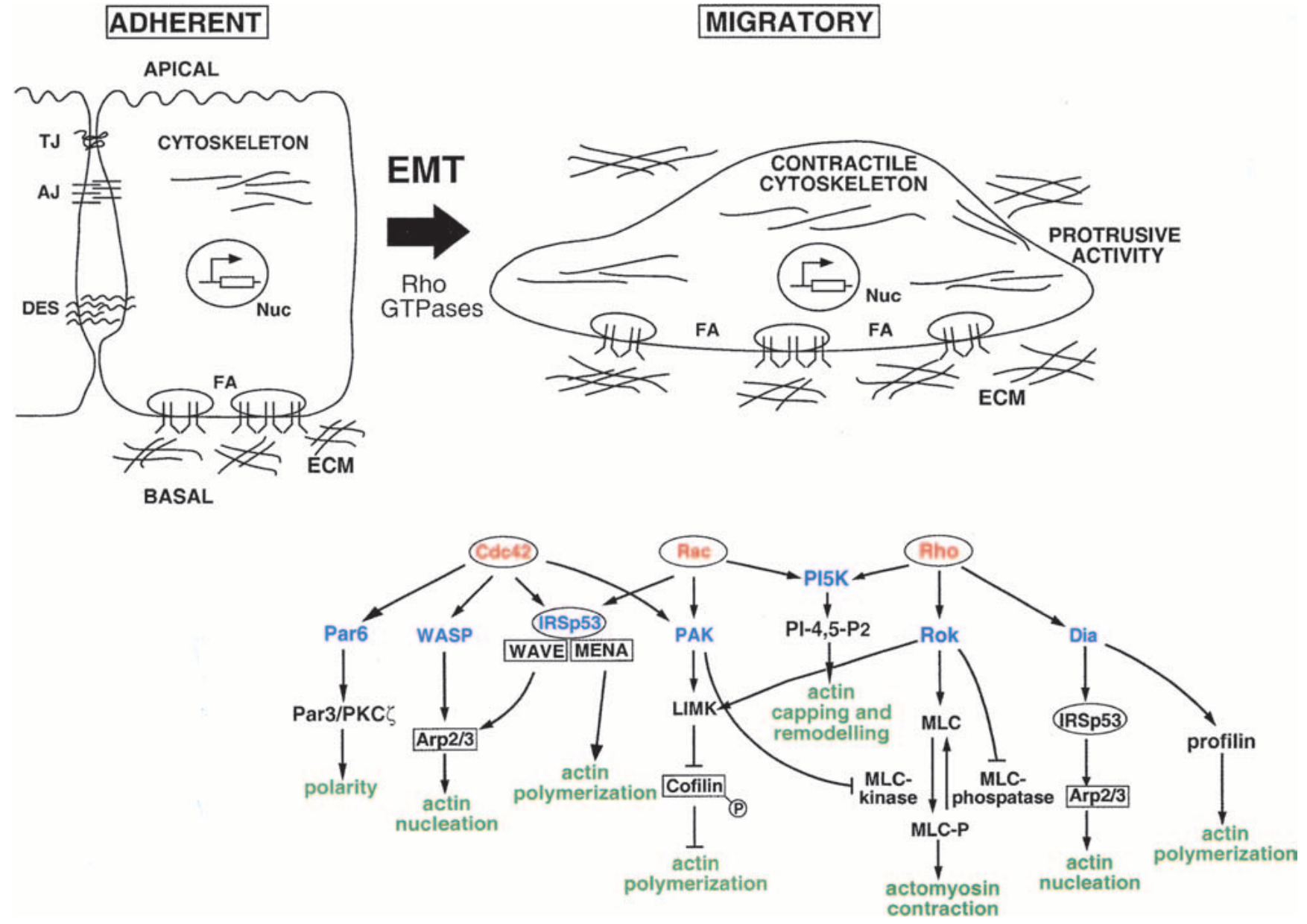

Figure 4. Transition of a typical adherent epithelial cell to a mesenchymal-like motile phenotype. Rho GTPase function is required at different steps during EMT transition (see text). An overview of Rho effectors mediating cytoskeletal rearrangements during cell migration is shown below. Cdc42 acts through several downstream effectors to trigger actin polymerization required for filopodia extension. Among these are the WASP proteins (including WASP and N-WASP), which mediate the activation of the Arp2/3 complex leading to nucleation of new actin filaments on the sides of existing ones. Activated Cdc42 also binds to members of the Pak family, stimulating LIMK, which in turn inhibits cofilin-mediated actin depolymerization. Pak also has been shown to phosphorylate and inactivate MLCK, resulting in the disassembly of stress fibers and focal adhesions, a process that is likely to contribute to motility. Cdc42 also can initiate actin filament assembly via the IRSp53:Mena complex. Finally, Cdc42 interacts with Par-6, a constituent of the Par/aPKC complex that is vital for the establishment of cellular polarity in diverse systems. Rac triggers F-actin accumulation to induce lamellipodia by activating a similar set of effector molecules. Several among these, such as the PAK and IRSp53 proteins are also Cdc42 effectors and analogous mechanisms as described above appears to apply for Rac's effects on actin nucleation and polymerization. In addition, Rac functions via a phosphatidyinositide 4-phosphate 5-kinase (PI 5-kinase) to produce the formation of $\mathrm{PI}(4,5) \mathrm{P} 2$. These lipids modulate the activity of capping proteins, removing them from the barbed ends of actin filaments. Activation of Rho regulates actomyosin contractility and causes actin reorganization to induce stress fibers and focal adhesion complexes (FAs). Members of at least two protein families appear to be required for Rho-induced assembly of stress fibers and FAs, the Rho-associated kinases (Rok) and the Dia members. Activation of Rho-kinase triggers an increase in myosin light chain (MLC) phosphorylation through inactivation of MLC phosphatase and likely also through direct phosphorylation of MLC. The increase in phosphorylated MLC stimulates contractility, promoting stress fiber formation. Rok functions in concert with Dia in the formation of stress fibers. Dia may contribute to stress fiber formation through its interaction with profilin, a G-actin binding protein. In addition, Dia has been reported to interact with the Cdc42/Rac effector IRSp53. Rok also stabilizes filamentous actin by phosphorylating LIM-kinase, which subsequently phosphorylates and inactivates cofilin. Similarly as for Rac, Rho may regulate the activity of PI 5-kinase to regulate capping activity.

three Rho GTPases in morphogenic responses are dorsal closure and the establishment of cell-cell junctions. Our deepening understanding of Rho-mediated signaling in epithelial morphogenesis surely will shed new light on the spatio-temporal regulation of Rho proteins. It also will be interesting to see whether the different isoforms of the above-discussed GTPases (e.g., RhoA vs. Rho B and RhoC) could play a distinct role in epithelial morphogenesis and whether other Rho GTPase family members, such as RhoD, TC21, Wrch-1, are involved and what the underlying mechanisms are. In this regard, recent genomic analysis, combining a protocol selecting 
for highly metastatic melanoma cells in mice with microarray analysis, identified the RhoC gene as a promoter of metastatic behavior (Clark et al. 2000). Another intriguing finding is that of the novel Cdc42-like GTPase Wrch-1 as a Wnt-1 transcriptional target (Tao et al. 2001). The Wnt signaling pathway, mostly through mutational analysis of the Wnt-family genes as well as the APC and $\beta$-catenin genes, has been implicated in tumorigenesis (Peifer and Polakis 2000; Polakis 2000). The contribution of Wrch-1 to the list of Wnt-responsive genes may help understand the downstream functions effected by Wnt-signaling, including the induction of morphological changes and disruption of cell-cell junctions. An even more challenging issue that remains to be addressed is to determine how processes that are taking place in epithelial monolayers are coordinated with stromal events to direct specific tissue morphogenesis, for example, of kidney tubules, thyroid follicles, or branching structures found in salvary glands and lung.

\section{Acknowledgments}

We thank Sarah Newey and Benjamin Boettner for their comments on the manuscript. L.V.A. is supported by grants from the $\mathrm{NIH}$, the U.S. Army, and the NF Foundation Inc. M.S. is supported by grants from the NIH and the Picower Foundation. Due to the wide range of the subject under review, we would like to apologize to those colleagues whose contributions have not been included.

\section{References}

Abercrombie, M. 1967. Contact inhibition: The phenomenon and its biological implications. Natl. Cancer Inst. Monogr. 26: 249-277.

Adams, C.L. and Nelson, W.J. 1998. Cytomechanics of cadherin-mediated cell-cell adhesion. Curr. Opin. Cell Biol. 10: $572-577$.

Adams, C.L., Chen, Y.T., Smith, S.J., and Nelson, W.J. 1998. Mechanisms of epithelial cell-cell adhesion and cell compaction revealed by high-resolution tracking of E-cadheringreen fluorescent protein. J. Cell Biol. 142: 1105-1119.

Adler, P.N. and Lee, H. 2001. Frizzled signaling and cell-cell interactions in planar polarity. Curr. Opin. Cell Biol. 13: 635-640.

Afshar, K., Stuart, B., and Wasserman, S.A. 2000. Functional analysis of the Drosophila FH protein in early embryonic development. Development 127: 1887-1897.

Andersen, S.S. 2000. Spindle assembly and the art of regulating microtubule dynamics by MAPs and Stathmin/Op18. Trends Cell Biol. 10: 261-267.

Arora, K., Dai, H., Kazuko, S.G., Jamal, J., O'Connor, M.B., Letsou, A., and Warrior, R. 1995. The Drosophila schnurri gene acts in the Dpp/TGF $\beta$ signaling pathway and encodes a transcription factor homologous to the human MBP family. Cell 81: 781-790.

Ashcroft, G.S. and Roberts, A.B. 2000. Loss of Smad3 modulates wound healing. Cytokine Growth Factor Rev. 11: 125-131.

Axelrod, J.D., Miller, J.R., Shulman, J.M., Moon, R.T., and Perrimon, N. 1998. Differential recruitment of Dishevelled provides signaling specificity in the planar cell polarity and Wingless signaling pathways. Genes \& Dev. 12: 2610-2622.

Barrett, K., Leptin, M., and Settleman, J. 1997. The Rho GTPase and a putative RhoGEF mediate a signaling pathway for the cell shape changes in Drosophila gastrulation. Cell 91: 905915.

Behrens, J., Mareel, M.M., Van Roy, F.M., and Birchmeier, W. 1989. Dissecting tumor cell invasion: Epithelial cells acquire invasive properties after the loss of uvomorulin-mediated cell-cell adhesion. J. Cell Biol. 108: 2435-2447.

Belmont, L., Mitchison, T., and Deacon, H.W. 1996. Catastrophic revelations about Op18/stathmin. Trends Biochem. Sci. 21: 197-198.

Belmont, L.D. and Mitchison, T.J. 1996. Identification of a protein that interacts with tubulin dimers and increases the catastrophe rate of microtubules. Cell 84: 623-631.

Bement, W.M., Forscher, P., and Mooseker, M.S. 1993. A novel cytoskeletal structure involved in purse string wound closure and cell polarity maintenance. J. Cell Biol. 121: 565578.

Bhowmick, N.A., Ghiassi, M., Bakin, A., Aakre, M., Lundquist, C.A., Engel, M.E., Arteaga, C.L., and Moses, H.L. 2001. Transforming growth factor- $\beta 1$ mediates epithelial to mesenchymal transdifferentiation through a RhoA-dependent mechanism. Mol. Biol. Cell 12: 27-36.

Birchmeier, W., Behrens, J., Weidner, K.M., Frixen, U.H., and Schipper, J. 1991. Dominant and recessive genes involved in tumor cell invasion. Curr. Opin. Cell Biol. 3: 832-840.

Boguski, M.S. and McCormick, F. 1993. Proteins regulating Ras and its relatives. Nature 366: 643-654.

Bourguignon, L.Y. 2001. CD44-mediated oncogenic signaling and cytoskeleton activation during mammary tumor progression. J. Mammary Gland Biol. Neoplasia 6: 287-297.

Boutros, M., Paricio, N., Strutt, D.I., and Mlodzik, M. 1998. Dishevelled activates JNK and discriminates between JNK pathways in planar polarity and wingless signaling. Cell 94: $109-118$.

Boyer, B., Valles, A.M., and Edme, N. 2000. Induction and regulation of epithelial-mesenchymal transitions. Biochem. Pharmacol. 60: 1091-1099.

Braga, V. 2000. Epithelial cell shape: Cadherins and small GTPases. Exp. Cell Res. 261: 83-90.

Braga, V.M., Mchesky, L.M., Hall, A., and Hotchin, N.A. 1997. The small GTPases Rho and Rac are required for the establishment of cadherin-dependent cell-cell contacts. J. Cell Biol. 137: 1421-1431.

Braga, V.M., Del Maschio, A., Machesky, L., and Dejana, E. 1999. Regulation of cadherin function by Rho and Rac: Modulation by junction maturation and cellular context. Mol. Biol. Cell 10: 9-22.

Braga, V.M., Betson, M., Li, X., and Lamarche-Vane, N. 2000. Activation of the small GTPase Rac is sufficient to disrupt cadherin-dependent cell-cell adhesion in normal human keratinocytes. Mol. Biol. Cell 11: 3703-3721.

Bray, S. 2000. Planar polarity: Out of joint? Curr. Biol. 10: R155R158.

Brill, S., Li, S., Lyman, C.W., Church, D.M., Wasmuth, J.J., Weissbach, L., Bernards, A., and Snijders, A.J. 1996. The Ras GTPase-activating-protein-related human protein IQGAP2 harbors a potential actin binding domain and interacts with calmodulin and Rho family GTPases. Mol. Cell. Biol. 16: 4869-4878.

Brock, J., Midwinter, K., Lewis, J., and Martin, P. 1996. Healing of incisional wounds in the embryonic chick wing bud: Characterization of the actin purse-string and demonstration of a requirement for Rho activation. J. Cell Biol. 135: 1097-1107.

Brummel, T.J., Twombly, V., Marques, G., Wrana, J.L., Newfeld, S.J., Attisano, L., Massague, J., O'Connor, M.B., and Gelbart, 
W.M. 1994. Characterization and relationship of Dpp receptors encoded by the saxophone and thick veins genes in Drosophila. Cell 78: 251-261.

Calautti, E., Cabodi, S., Stein, P.L., Hatzfeld, M., Kedersha, N., and Paolo Dotto, G. 1998. Tyrosine phosphorylation and src family kinases control keratinocyte cell-cell adhesion. J. Cell Biol. 141: 1449-1465.

Calautti, E., Grossi, M., Mammucari, C., Aoyama, Y., Pirro, M., Ono, Y., Li, J., and Dotto, G.P. 2002. Fyn tyrosine kinase is a downstream mediator of Rho/PRK2 function in keratinocyte cell-cell adhesion. J. Cell Biol. 156: 137-148.

Cassimeris, L. 2002. The oncoprotein 18/stathmin family of microtubule destabilizers. Curr. Opin. Cell Biol. 14: 18-24.

Castrillon, D.H. and Wasserman, S.A. 1994. Diaphanous is required for cytokinesis in Drosophila and shares domains of similarity with the products of the limb deformity gene. Development 120: 3367-3377.

Chailley, B., Nicolas, G., and Laine, M.C. 1989. Organization of actin microfilaments in the apical border of oviduct ciliated cells. Biol. Cell 67: 81-90.

Cheresh, D.A., Leng, J., and Klemke, R.L. 1999. Regulation of cell contraction and membrane ruffling by distinct signals in migratory cells. J. Cell Biol. 146: 1107-1116.

Christopher, R.A. and Guan, J.L. 2000. To move or not: How a cell responds. Int. J. Mol. Med. 5: 575-581.

Ciapponi, L., Jackson, D.B., Mlodzik, M., and Bohmann, D. 2001. Drosophila Fos mediates ERK and JNK signals via distinct phosphorylation sites. Genes \& Dev. 15: 1540-1553.

Clark, E.A., Golub, T.R., Lander, E.S., and Hynes, R.O. 2000. Genomic analysis of metastasis reveals an essential role for RhoC. Nature 406: 532-535.

Cohen, D., Musch, A., and Rodriguez-Boulan, E. 2001. Selective control of basolateral membrane protein polarity by cdc 42 . Traffic 2: 556-564.

Condeelis, J. 2001. How is actin polymerization nucleated in vivo? Trends Cell Biol. 11: 288-293.

Conradt, B. 2001. Cell engulfment, no sooner ced than done. Dev. Cell 1: 445-447.

Cui, W., Fowlis, D.J., Bryson, S., Duffie, E., Ireland, H., Balmain, A., and Akhurst, R.J. 1996. TGF $\beta 1$ inhibits the formation of benign skin tumors, but enhances progression to invasive spindle carcinomas in transgenic mice. Cell 86: 531-542.

D'Souza-Schorey, C., Boettner, B., and Van Aelst, L. 1998. Rac regulates integrin-mediated spreading and increased adhesion of T lymphocytes. Mol. Cell. Biol. 18: 3936-3946.

Danjo, Y. and Gipson, I.K. 1998. Actin "purse string" filaments are anchored by E-cadherin-mediated adherens junctions at the leading edge of the epithelial wound, providing coordinated cell movement. J. Cell Sci. 111: 3323-3332.

Daub, H., Gevaert, K., Vandekerckhove, J., Sobel, A., and Hall, A. 2001. Rac/Cdc42 and p65PAK regulate the microtubuledestabilizing protein stathmin through phosphorylation at serine 16. J. Biol. Chem. 276: 1677-1680.

de Curtis, I. 2001. Cell migration: GAPs between membrane traffic and the cytoskeleton. EMBO Rep. 2: 277-281.

Dong, L.Q., Landa, L.R., Wick, M.J., Zhu, L., Mukai, H., Ono, Y., and Liu, F. 2000. Phosphorylation of protein kinase $\mathrm{N}$ by phosphoinositide-dependent protein kinase-1 mediates insulin signals to the actin cytoskeleton. Proc. Natl. Acad. Sci. 97: 5089-5094.

Drubin, D.G. and Nelson, W.J. 1996. Origins of cell polarity. Cell 84: 335-344.

Duband, J.L., Monier, F., Delannet, M., and Newgreen, D. 1995. Epithelium-mesenchyme transition during neural crest development. Acta. Anat. 154: 63-78.

Eaton, S. 1997. Planar polarization of Drosophila and vertebrate epithelia. Curr. Opin. Cell Biol. 9: 860-866.

Eaton, S. and Simons, K. 1995. Apical, basal, and lateral cues for epithelial polarization. Cell 82: 5-8

Eaton, S., Auvinen, P., Luo, L., Jan, Y.N., and Simons, K. 1995. CDC42 and Rac1 control different actin-dependent processes in the Drosophila wing disc epithelium. J. Cell Biol. 131: $151-164$.

Eaton, S., Wepf, R., and Simons, K. 1996. Roles for Rac1 and Cdc42 in planar polarization and hair outgrowth in the wing of Drosophila. J. Cell Biol. 135: 1277-1289.

Ebnet, K., Suzuki, A., Horikoshi, Y., Hirose, T., Meyer Zu Brickwedde, M.K., Ohno, S., and Vestweber, D. 2001. The cell polarity protein ASIP/PAR-3 directly associates with junctional adhesion molecule (JAM). EMBO J. 20: 3738-3748.

Ellis, S. and Mellor, H. 2000. Regulation of endocytic traffic by Rho family GTPases. Trends Cell Biol. 10: 85-88.

Erickson, M.R., Galletta, B.J., and Abmayr, S.M. 1997. Drosophila myoblast city encodes a conserved protein that is essential for myoblast fusion, dorsal closure, and cytoskeletal organization. J. Cell Biol. 138: 589-603.

Erickson, J.W., Zhang, C., Kahn, R.A., Evans, T., and Cerione, R.A. 1996. Mammalian Cdc42 is a brefeldin A-sensitive component of the Golgi apparatus. I. Biol. Chem. 271: 26850-26854.

Etienne-Manneville, S. and Hall, A. 2001. Integrin-mediated activation of $\mathrm{Cdc} 42$ controls cell polarity in migrating astrocytes through PKC $\zeta$. Cell 106: 489-98.

Evers, E.E., Zondag, G.C.M., Malliri, A., Price, L.S., ten Klooster, J.-P., van der Kammen, R.A., and Collard, J.G. 2000. Rho family proteins in cell adhesion and cell migration. Europ. J. Cancer 36: 1269-1274.

Fanto, M., Weber, U., Strutt D.I., and Mlodzik, M. 2000 Nuclear signaling by Rac and Rho GTPases is required in the establishment of epithelial planar polarity in the Drosophila eye. Curr. Biol. 10: 979-988.

Fenteany, G., Janmey, P.A., and Stossel, T.P. 2000. Signaling pathways and cell mechanics involved in wound closure by epithelial cell sheets. Curr. Biol. 10: 831-818.

Fincham, V.J., Unlu, M., Brunton, V.G., Pitts, J.D., Wyke, J.A., and Frame, M.C. 1996. Translocation of Src kinase to the cell periphery is mediated by the actin cytoskeleton under the control of the Rho family of small G proteins. J. Cell Biol. 135: 1551-1564.

Fukata, M., Kuroda, S., Nakagawa, M., Kawajiri, A., Itoh, N., Shoji, I., Matsuura, Y., Yonehara, S., Fujisawa, H., Kikuchi, A., et al. 1999. Cdc42 and Rac1 regulate the interaction of IQGAP1 with $\beta$-catenin. J. Biol. Chem. 274: 26044-26050.

Genova, J.L., Jong, S., Camp, J.T., and Fehon, R.G. 2000. Functional analysis of $\mathrm{Cdc} 42$ in actin filament assembly, epithelial morphogenesis, and cell signaling during Drosophila development. Dev. Biol. 221: 181-194.

Gherardi, E. and Stoker, M. 1991. Hepatocyte growth factorscatter factor: Mitogen, motogen, and met. Cancer Cells 3: 227-232.

Gimond, C., van Der, F.A., van Delft, S., Brakebusch, C., Kuikman, I., Collard, J.G., Fassler, R., and Sonnenberg, A. 1999. Induction of cell scattering by expression of $\beta 1$ integrins in $\beta 1$-deficient epithelial cells requires activation of members of the rho family of GTPases and downregulation of cadherin and catenin function. J. Cell Biol. 147: 1325-1340.

Glise, B. and Noselli, S. 1997. Coupling of Jun amino-terminal kinase and Decapentaplegic signaling pathways in Drosophila morphogenesis. Genes \& Dev. 11: 1738-1747.

Glise, B., Bourbon, H., and Noselli, S. 1995. hemipterous encodes a novel Drosophila MAP kinase kinase, required for epithelial cell sheet movement. Cell 83: 451-461. 
Goberdhan, D.C. and Wilson, C. 1998. JNK, cytoskeletal regulator and stress response kinase? A Drosophila perspective. BioEssays 20: 1009-1019.

Goldfinger, L.E., Hopkinson, S.B., deHart, G.W., Collawn, S., Couchman, J.R., and Jones, J.C. 1999. The $\alpha 3$ laminin subunit, $\alpha 6 \beta 4$ and $\alpha 3 \beta 1$ integrin coordinately regulate wound healing in cultured epithelial cells and in the skin. J. Cell Sci. 112: 2615-2629.

Gomez, T.M., Robles, E., Poo, M., and Spitzer, N.C. 2001. Filopodial calcium transients promote substrate-dependent growth cone turning. Science 291: 1983-1987.

Grande, J.P. 1997. Role of transforming growth factor-beta in tissue injury and repair. Proc. Soc. Exp. Biol. Med. 214: $27-$ 40.

Grieder, N.C., Nellen, D., Burke, R., Basler, K., and Affolter, M. 1995. Schnurri is required for Drosophila Dpp signaling and encodes a zinc finger protein similar to the mammalian transcription factor PRDII-BF1. Cell 81: 791-800.

Grose, R. and Martin, P. 1999. Parallels between wound repair and morphogenesis in the embryo. Semin. Cell Dev. Biol. 10: 395-404.

Gulli, M.P. and Peter, M. 2001. Temporal and spatial regulation of Rho-type guanine-nucleotide exchange factors: The yeast perspective. Genes \& Dev. 15: 365-379.

Gumienny, T.L., Brugnera, E., Tosello-Trampont, A.C., Kinchen, J.M., Haney, L.B., Nishiwaki, K., Walk, S.F., Nemergut, M.E., Macara, I.G., Francis, R., et al. 2001. CED-12/ ELMO, a novel member of the CrkII/Dock180/Rac pathway, is required for phagocytosis and cell migration. Cell 107: 2741.

Gundersen, G.G., Kreitzer, G., Cook, T., and Liao, G. 1998. Microtubules as determinants of cellular polarity. Biol. Bull. 194: 358-360.

Habas, R., Kato, Y., and He, X. 2001. Wnt/Frizzled activation of rho regulates vertebrate gastrulation and requires a novel formin homology protein daam1. Cell 107: 843-854.

Hakeda-Suzuki, S., Ng, J., Tzu, J., Dietzl, G., Sun, Y., Harms, M., Nardine, T., Luo, L., and Dickson, B. 2002. Rac function and regulation during Drosophila development. Nature 416: 438-442.

Hall, A. 1998. Rho GTPases and the actin cytoskeleton. Science 279: $509-514$.

Hall, A. and Nobes, C.D. 2000. Rho GTPases: Molecular switches that control the organization and dynamics of the actin cytoskeleton. Philos. Trans. R Soc. Lond. B Biol. Sci. 355: 965-970.

Halsell, S.R., Chu, B.I., and Kiehart, D.P. 2000. Genetic analysis demonstrates a direct link between rho signaling and nonmuscle myosin function during Drosophila morphogenesis. Genetics 155: 1253-1265.

Harden, N., Loh, H.Y., Chia, W., and Lim, L. 1995. A dominant inhibitory version of the small GTP-binding protein Rac disrupts cytoskeletal structures and inhibits developmental cell shape changes in Drosophila. Development 121: 903 914.

Harden, N., Lee, J., Loh, H.Y., Ong, Y.M., Tan, I., Leung, T., Manser, E., and Lim, L. 1996. A Drosophila homolog of the Rac- and Cdc42-activated serine/threonine kinase PAK is a potential focal adhesion and focal complex protein that colocalizes with dynamic actin structures. Mol. Cell. Biol 16: 1896-1908.

Harden, N., Ricos, M., Ong, Y.M., Chia, W., and Lim, L. 1999. Participation of small GTPases in dorsal closure of the Drosophila embryo: Distinct roles for Rho subfamily proteins in epithelial morphogenesis. J. Cell Sci. 112: 273-284.

Hasegawa, H., Kiyokawa, E., Tanaka, S., Nagashima, K., Gotoh,
N., Shibuya, M., Kurata, T., and Matsuda, M. 1996 DOCK180, a major CRK-binding protein, alters cell morphology upon translocation to the cell membrane. Mol. Cell. Biol. 16: 1770-1776.

Hay, E.D. 1995. An overview of epithelio-mesenchymal transformation. Acta Anat. 154: 8-20.

Heath, J.P. 1996. Epithelial cell migration in the intestine. Cell Biol. Int. 20: 139-146.

Hollenbeck, P. 2001. Cytoskeleton: Microtubules get the signal. Curr. Biol. 11: R820-R823.

Hordijk, P.L., ten Klooster, J.P., van der Kammen, R.A., Michiels, F., Oomen, L.C., and Collard, J.G. 1997. Inhibition of invasion of epithelial cells by Tiam1-Rac signaling. Science 278: 1464-1466.

Hotchin, N.A. and Hall, A. 1995. The assembly of integrin adhesion complexes requires both extracellular matrix and intracellular rho/rac GTPases. J. Cell Biol. 131: 1857-1865.

Hou, X.S., Goldstein, E.S., and Perrimon, N. 1997. Drosophila Jun relays the Jun amino-terminal kinase signal transduction pathway to the Decapentaplegic signal transduction pathway in regulating epithelial cell sheet movement. Genes \& Dev. 11: 1728-1737.

Howell, B., Deacon, H., and Cassimeris, L. 1999. Decreasing oncoprotein 18/stathmin levels reduces microtubule catastrophes and increases microtubule polymer in vivo. J. Cell Sci. 112: 3713-3722.

Ishizaki, T., Morishima, Y., Okamoto, M., Furuyashiki, T., Kato, T., and Narumiya, S. 2001. Coordination of microtubules and the actin cytoskeleton by the Rho effector mDial. Nat. Cell Biol. 3: 8-14.

Itoh, M., Sasaki, H., Furuse, M., Ozaki, H., Kita, T., and Tsukita, S. 2001. Junctional adhesion molecule (JAM) binds to PAR-3: A possible mechanism for the recruitment of PAR-3 to tight junctions. J. Cell Biol. 154: 491-497.

Jacinto, A., Wood, W., Balayo, T., Turmaine, M., MartinezArias, A., and Martin, P. 2000. Dynamic actin-based epithelial adhesion and cell matching during Drosophila dorsal closure. Curr. Biol. 10: 1420-1426.

Jacinto, A., Martinez-Arias, A., and Martin, P. 2001. Mechanisms of epithelial fusion and repair. Nat. Cell Biol. 3: E117E123.

Jasper, H., Benes, V., Schwager, C., Sauer, S., Clauder-Munster, S., Ansorge, W., and Bohmann, D. 2001. The genomic response of the Drosophila embryo to JNK signaling. Dev. Cell 1: $579-586$.

Joberty, G., Petersen, C., Gao, L., and Macara, I.G. 2000. The cell-polarity protein Par6 links Par3 and atypical protein kinase C to Cdc42. Nat. Cell Biol. 2: 531-539.

Jones, G.E., Allen, W.E., and Ridley, A.J. 1998. The Rho GTPases in macrophage motility and chemotaxis. Cell Adhes. Commun. 6: 237-245.

Jou, T.-S., Schneeberger, E.E., and Nelson, W.J. 1998. Structural and functional regulation of tight junctions by RhoA and Rac1 small GTPases. J. Cell Biol. 142: 101-115.

Kaibuchi, K., Kuroda, S., and Amano, M. 1999a. Regulation of the cytoskeleton and cell adhesion by the Rho family GTPases in mammalian cells. Annu. Rev. Biochem. 68: 459486.

Kaibuchi, K., Kuroda, S., Fukata, M., and Nakagawa, M. 1999b. Regulation of cadherin-mediated cell-cell adhesion by the Rho family GTPases. Curr. Opin. Cell Biol. 11: 591-596.

Keely, P.J., Westwick, J.K., Whitehead, I.P., Der, C.J., and Parise, L.V. 1997. Cdc42 and Rac1 induce integrin-mediated cell motility and invasiveness through PI(3)K. Nature 390: 632636.

Keely, P., Parise, L., and Juliano, R. 1998. Integrins and GTPases 
in tumour cell growth, motility, and invasion. Trends Cell Biol. 8: 101-106.

Kiehart, D.P. 1999. Wound healing: The power of the purse string. Curr. Biol. 9: R602-R605.

Kiehart, D.P., Galbraith, C.G., Edwards, K.A., Rickoll, W.L., and Montague, R.A. 2000. Multiple forces contribute to cell sheet morphogenesis for dorsal closure in Drosophila. J. Cell Biol. 149: 471-490.

Kim, S.H., Li, Z., and Sacks, D.B. 2000. E-cadherin-mediated cell-cell attachment activates Cdc42. J. Biol. Chem. 275: 36999-37005.

Kiyokawa, E., Hashimoto, Y., Kobayashi, S., Sugimura, H., Kurata, T., and Matsuda, M. 1998. Activation of Racl by a Crk SH3-binding protein, DOCK180. Genes \& Dev. 12: 33313336.

Klemke, R.L., Leng, J., Molander, R., Brooks, P.C., Vuori, K., and Cheresh, D.A. 1998. CAS/Crk coupling serves as a "molecular switch" for induction of cell migration. J. Cell Biol. 140: 961-972.

Klingensmith, J., Nusse, R., and Perrimon, N. 1994. The Drosophila segment polarity gene dishevelled encodes a novel protein required for response to the wingless signal. Genes \& Dev. 8: 118-130.

Knust, E. 1997. Drosophila morphogenesis: Movements behind the edge. Curr. Biol. 7: R558-R561.

Kockel, L., Zeitlinger, J., Staszewski, L.M., Mlodzik, M., and Bohmann, D. 1997. Jun in Drosophila development: Redundant and nonredundant functions and regulation by two MAPK signal transduction pathways. Genes \& Dev. 11: $1748-1758$.

Kodama, A., Takaishi, K., Nakano, K., Nishioka, H., and Takai, Y. 1999. Involvement of Cdc42 small G protein in cell-cell adhesion, migration, and morphology of MDCK cells. Oncogene 18: 3996-4006.

Kollmar, R. 1999. Who does the hair cell's 'do? Rho GTPases and hair-bundle morphogenesis. Curr. Opin. Neurobiol. 9: 394-398.

Kotani, H., Takaishi, K., Sasaki, T., and Takai, Y. 1997. Rho regulates association of both the ERM family and vinculin with the plasma membrane in MDCK cells. Oncogene 14: 1705-1713.

Kovacs, E.M., Ali, R.G., McCormack, A.J., and Yap, A.S. 2002. E-cadherin homophilic ligation directly signals through Rac and phosphatidylinositol 3-kinase to regulate adhesive contacts. J. Biol. Chem. 277: 6708-6718.

Krasnow, R.E., Wong, L.L., and Adler, P.N. 1995. Dishevelled is a component of the frizzled signaling pathway in Drosophila. Development 121: 4095-4102.

Kroschewski, R., Hall, A., and Mellman, I. 1999. Cdc42 controls secretory and endocytic transport to the basolateral plasma membrane of MDCK cells. Nat. Cell Biol. 1: 8-13.

Krugmann, S., Jordens, I., Gevaert, K., Driessens, M., Vandekerckhove, J., and Hall, A. 2001. Cdc42 induces filopodia by promoting the formation of an IRSp53:Mena complex. Curr. Biol. 11: 1645-1655.

Kuroda, S., Fukata, M., Kobayashi, K., Nakafuku, M., Nomura, N., Iwamatsu, A., and Kaibuchi, K. 1996. Identification of IQGAP as a putative target for the small GTPases, Cdc42 and Rac1. J. Biol. Chem. 271: 23363-22367.

Kuroda, S., Fukata, M., Nakagawa, M., Fujii, K., Nakamura, T., Ookubo, T., Izawa, I., Nagase, T., Nomura, N., Tani, H., et al. 1998. Role of IQGAP1, a target of the small GTPases Cdc42 and Rac1, in regulation of E-cadherin-mediated cellcell adhesion. Science 281: 832-835.

Larsson, N., Segerman, B., Howell, B., Fridell, K., Cassimeris, L., and Gullberg, M. 1999. Op18/stathmin mediates multiple region-specific tubulin and microtubule-regulating activities. J. Cell Biol. 146: 1289-1302.

Lauffenburger, D.A. and Horwitz, A.F. 1996. Cell migration: A physically integrated molecular process. Cell 84: 359-369.

Letsou, A., Arora, K., Wrana, J.L., Simin, K., Twombly, V., Jamal, J., Staehling-Hampton, K., Hoffmann, F.M., Gelbart, W.M., Massague, J., et al. 1995. Drosophila Dpp signaling is mediated by the punt gene product: A dual ligand-binding type II receptor of the TGF $\beta$ receptor family. Cell 80: 899908.

Li, S., Wang, Q., Chakladar, A., Bronson, R.T., and Bernards, A 2000. Gastric hyperplasia in mice lacking the putative Cdc42 effector IQGAP1. Mol. Cell. Biol. 20: 697-701.

Lin, D., Edwards, A.S., Fawcett, J.P., Mbamalu, G., Scott, J.D., and Pawson, T. 2000. A mammalian PAR-3-PAR-6 complex implicated in Cdc42/Rac1 and aPKC signalling and cell polarity. Nat. Cell Biol. 2: 540-547.

Llimargas, M. and Lawrence, P.A. 2001. Seven Wnt homologues in Drosophila: A case study of the developing tracheae. Proc. Nat1. Acad. Sci. 98: 14487-14492.

Lotz, M.M., Nusrat, A., Madara, J.L., Ezzell, R., Wewer, U.M. and Mercurio, A.M. 1997. Intestinal epithelial restitution. Involvement of specific laminin isoforms and integrin laminin receptors in wound closure of a transformed model epithelium. Am. J. Pathol. 150: 747-760.

Lotz, M.M., Rabinovitz, I., and Mercurio, A.M. 2000. Intestinal restitution: Progression of actin cytoskeleton rearrangements and integrin function in a model of epithelial wound healing. Am. J. Pathol. 156: 985-996.

Lu, Y. and Settleman, J. 1999a. The Drosophila Pkn protein kinase is a Rho/Rac effector target required for dorsal closure during embryogenesis. Genes \& Dev. 13: 1168-1180.

- 1999b. The role of rho family GTPases in development: Lessons from Drosophila melanogaster. Mol. Cell. Biol. Res. Commun. 1: 87-94.

Lynch, E.D., Lee, M.K., Morrow, J.E., Welcsh, P.L., León, P.E., and King, M. 1997. Nonsyndromic deafness DFNA1 associated with mutation of a human homolog of the Drosophila gene diaphanous. Science 278: 1315-1318.

Machesky, L.M. and Gould, K.L. 1999. The Arp2/3 complex: A multifunctional actin organizer. Curr. Opin. Cell Biol. 11: $117-121$

Machesky, L.M. and Insall, R.H. 1999. Signaling to actin dynamics. J. Cell Biol. 146: 267-272.

MacKrell, A.J., Blumberg, B., Haynes, S.R., and Fessler, J.H. 1988. The lethal myospheroid gene of Drosophila encodes a membrane protein homologous to vertebrate integrin beta subunits. Proc. Natl. Acad. Sci. 85: 2633-2637.

Madara, J.L. 1998. Regulation of the movement of solutes across tight junctions. Annu. Rev. Physiol. 60: 143-159.

Magie, C.R., Meyer, M.R., Gorsuch, M.S., and Parkhurst, S.M. 1999. Mutations in the Rhol small GTPase disrupt morphogenesis and segmentation during early Drosophila development. Development 126: 5353-5364.

Markwald, R., Eisenberg, C., Eisenberg, L., Trusk, T., and Sugi, Y. 1996. Epithelial-mesenchymal transformations in early avian heart development. Acta Anat. 156: 173-186.

Martin, P. 1997. Wound healing —aiming for perfect skin regeneration. Science 276: 75-81.

Martin, P. and Lewis, J. 1992. Actin cables and epidermal movement in embryonic wound healing. Nature 360: 179-183.

Martin-Blanco, E. and Knust, E. 2001. Epithelial morphogenesis: Filopodia at work. Curr. Biol. 11: R28-R31.

Martin-Blanco, E., Gampel, A., Ring, J., Virdee, K., Kirov, N., Tolkovsky, A.M., and Martinez-Arias, A. 1998. puckered encodes a phosphatase that mediates a feedback loop regulating 
JNK activity during dorsal closure in Drosophila. Genes \& Dev. 12: 557-570.

Massague, J. 1999. Wounding Smad. Nat. Cell Biol. 1: E117E119.

McLeod, C., Thornley, A., Veale, R., and Scott, E. 1990. The anchorage-dependent and -independent growth of a human SCC cell line: The roles of TGF $\alpha /$ EGF and TGF $\beta$. Br. J. Cancer 61: 267-269.

Mercurio, A.M., Rabinovitz, I., and Shaw, L.M. 2001. The $\alpha 6 \beta 4$ integrin and epithelial cell migration. Curr. Opin. Cell Biol. 13: $541-545$.

Mlodzik, M. 1999. Planar polarity in the Drosophila eye: A multifaceted view of signaling specificity and cross-talk. EMBO J. 18: 6873-6879.

Mlodzik, M. 2000. Spiny legs and prickled bodies: New insights and complexities in planar polarity establishment. BioEssays 22: $311-315$.

Montell, D.J. 1999. The genetics of cell migration in Drosophilia melanogaster and Caenorhabditis elegans development. Development 126: 3035-3046.

Mostov, K.E., Verges, M., and Altschuler, Y. 2000. Membrane traffic in polarized epithelial cells. Curr. Opin. Cell Biol. 12: 483-490.

Müller, U. and Littlewood-Evans, A. 2001. Mechanisms that regulate mechanosensory hair cell differentiation. Trends Cell Biol. 11: 334-342.

Musch, A., Cohen, D., Kreitzer, G., and Rodriguez-Boulan, E. 2001. cdc42 regulates the exit of apical and basolateral proteins from the trans-Golgi network. EMBO J. 20: 2171-2179.

Nabi, I.R. 1999. The polarization of the motile cell. J. Cell Sci. 112: $1803-1811$.

Nakagawa, M., Fukata, M., Yamaga, M., Itoh, N., and Kaibuchi, K. 2001. Recruitment and activation of Rac1 by the formation of E-cadherin-mediated cell-cell adhesion sites. J. Cell Sci. 114: 1829-1838.

Nellen, D., Affolter, M., and Basler, K. 1994. Receptor serine/ threonine kinases implicated in the control of Drosophila body pattern by decapentaplegic. Cell 78: 225-237.

Nelson, W.J., Yeaman, C., and Grindstaff, K.K. 2000. Spatial cues for cellular assymmetry in polarized epithelia. In Cell polarity. Frontiers in molecular biology (ed. D.G. Drubin), pp. 106-140. Oxford University Press, Oxford, UK.

Ng, J., Nardine, T., Harms, M., Tzu, J., Goldstein, A., Sun, Y., Dietzl, G., Dickson, B., and Luo, L. 2002. Rac GTPase control axon growth, guidance, and branching. Nature 416: 442447.

Nobes, C.D. and Hall, A. 1999. Rho GTPases control polarity, protrusion, and adhesion during cell movement. J. Cell Biol. 144: $1235-1244$.

Nolan, K.M., Barrett, K., Lu, Y., Hu, K.Q., Vincent, S., and Settleman, J. 1998. Myoblast city, the Drosophila homolog of DOCK180/CED-5, is required in a Rac signaling pathway utilized for multiple developmental processes. Genes \& Dev. 12: 3337-3342.

Noren, N.K., Niessen, C.M., Gumbiner, B.M., and Burridge, K. 2001. Cadherin engagement regulates Rho family GTPases. J. Biol. Chem. 276: 33305-33308.

Noselli, S. 1998. JNK signaling and morphogenesis in Drosophila. Trends Genet. 14: 33-38.

Nusrat, A., Giry, M., Turner, J.R., Colgan, S.P., Parkos, C.A., Carnes, D., Lemichez, E., Boquet, P., and Madara, J.L. 1995. Rho protein regulates tight junctions and perijunctional actin organization in polarized epithelia. Proc. Nat1. Acad. Sci. 92: 10629-10633.

O'Brien, L.E., Jou, T.S., Pollack, A.L., Zhang, Q., Hansen, S.H., Yurchenco, P., and Mostov, K.E. 2001. Rac1 orientates epi- thelial apical polarity through effects on basolateral laminin assembly. Nat. Cell Biol. 3: 831-838.

O'Kane, S. and Ferguson, M.W. 1997. Transforming growth factor beta $\mathrm{s}$ and wound healing. Int. J. Biochem. Cell Biol. 29: 63-78.

Oft, M., Heider, K.H., and Beug, H. 1998. TGF $\beta$ signaling is necessary for carcinoma cell invasiveness and metastasis. Curr. Biol. 8: 1243-1252.

Ohno, S. 2001. Intercellular junctions and cellular polarity: The PAR-aPKC complex, a conserved core cassette playing fundamental roles in cell polarity. Curr. Opin. Cell Biol. 13: 641-648.

Otto, I.M., Raabe, T., Rennefahrt, U.E., Bork, P., Rapp, U.R., and Kerkhoff, E. 2000. The p150-Spir protein provides a link between c-Jun $\mathrm{N}$-terminal kinase function and actin reorganization. Curr. Biol. 10: 345-348.

Padgett, R.W., St Johnston, R.D., and Gelbart, W.M. 1987. A transcript from a Drosophila pattern gene predicts a protein homologous to the transforming growth factor- $\beta$ family. $\mathrm{Na}$ ture 325: 81-84.

Palazzo, A.F., Cook, T.A., Alberts, A.S., and Gundersen, G.G. 2001a. mDia mediates Rho-regulated formation and orientation of stable microtubules. Nat. Cell Biol. 3: 723-729.

Palazzo, A.F., Joseph, H.L., Chen, Y.-J., Dujardin, D.L., Alberts, A.S., Pfister, K.K., Valee, R.B., and Gundersen, G.G. 2001 b. Cdc42, dynein, and dynactin regulate MTOC reorientation independent of Rho-regulated microtubule stabilization. Curr. Biol. 11: 1536-1541.

Peifer, M. and Polakis, P. 2000. Wnt signaling in oncogenesis and embryogenesis-a look outside the nucleus. Science 287: 1606-1609.

Penton, A., Chen, Y., Staehling-Hampton, K., Wrana, J.L., Attisano, L., Szidonya, J., Cassill, J.A., Massague, J., and Hoffmann, F.M. 1994. Identification of two bone morphogenetic protein type I receptors in Drosophila and evidence that Brk25D is a decapentaplegic receptor. Cell 78: 239-250.

Piek, E., Heldin, C.H., and Ten Dijke, P. 1999. Specificity, diversity, and regulation in TGF- $\beta$ superfamily signaling. FASEB J. 13: 2105-2124.

Pignatelli, M. 1998. Integrins, cadherins, and catenins: Molecular cross-talk in cancer cells. J. Pathol. 186: 1-2.

Pla, P., Moore, R., Morali, O.G., Grille, S., Martinozzi, S., Delmas, V., and Larue, L. 2001. Cadherins in neural crest cell development and transformation. J. Cell Physiol. 189: 121132.

Polakis, P. 2000. Wnt signaling and cancer. Genes \& Dev. 14: $1837-1851$.

Portella, G., Cumming, S.A., Liddell, J., Cui, W., Ireland, H., Akhurst, R.J., and Balmain, A. 1998. Transforming growth factor beta is essential for spindle cell conversion of mouse skin carcinoma in vivo: Implications for tumor invasion. Cell Growth Differ. 9: 393-404.

Potempa, S. and Ridley, A.J. 1998. Activation of both MAP kinase and phosphatidylinositide 3-kinase by Ras is required for hepatocyte growth factor/scatter factor-inducted adherens junction disassembly. Mol. Biol. Cell 9: 2185-2200.

Price, L.S. and Collard, J.G. 2001. Regulation of the cytoskeleton by Rho-family GTPases: Implications for tumour cell invasion. Semin. Cancer Biol. 11: 167-173.

Qiu, R.G., Abo, A., and Steven, M.G. 2000. A human homolog of the C. elegans polarity determinant Par-6 links Rac and Cdc42 to PKC $\zeta$ signaling and cell transformation. Curr. Biol. 10: 697-707.

Quinlan, M.P. 1999. Rac regulates the stability of the adherens junction and its components, thus affecting epithelial cell differentiation and transformation. Oncogene 18: 6434- 
6442.

Raich, W.B., Agbunag, C., and Hardin, J. 1999. Rapid epithelialsheet sealing in the Caenorhabditis elegans embryo requires cadherin-dependent filopodial priming. Curr. Biol. 9: 11391146.

Ricos, M.G., Harden, N., Sem, K.P., Lim, L., and Chia, W. 1999. Dcdc42 acts in TGF- $\beta$ signaling during Drosophila morphogenesis: Distinct roles for the Drac1/JNK and Dcdc42/TGF- $\beta$ cascades in cytoskeletal regulation. J. Cell Sci. 112: 12251235.

Ridley, A.J. 2001a. Rho GTPases and cell migration. J. Cell Biol. 114: 2713-2722.

- 2001b. Rho proteins: Linking signaling with membrane trafficking. Traffic 2: 303-310.

Ridley, A.J., Comoglio, P.M., and Hall, A. 1995. Regulation of scatter factor/hepatocyte growth factor responses by Ras, Rac, and Rho in MDCK cells. Mol. Cell. Biol. 15: 1110-1122.

Ridley, A.J., Allen, W.E., Peppelenbosch, M., and Jones, G.E. 1999. Rho family proteins and cell migration. Biochem. Soc. Symp. 65: 111-123.

Riesgo-Escovar, J.R. and Hafen, E. 1997a. Common and distinct roles of DFos and DJun during Drosophila development. Science 278: 669-672.

- 1997b. Drosophila Jun kinase regulates expression of decapentaplegic via the ETS-domain protein Aop and the AP-1 transcription factor DJun during dorsal closure. Genes \& Dev. 11: 1717-1727.

Rojas, R., Ruiz, W.G., Leung, S.M., Jou, T.S., and Apodaca, G. 2001. Cdc42-dependent modulation of tight junctions and membrane protein traffic in polarized madin-darby canine kidney cells. Mol. Biol. Cell 12: 2257-2274.

Rosen, E.M., Meromsky, L., Setter, E., Vinter, D.W., and Goldberg, I.D. 1990. Smooth muscle-derived factor stimulates mobility of human tumor cells. Invasion Metastasis 10: 4964.

Rottner, K., Hall, A., and Small, J.V. 1999. Interplay between Rac and Rho in the control of substrate contact dynamics. Curr. Biol. 9: 640-648.

Royal, I., Lamarche-Vane, N., Lamorte, L., Kaibuchi, K., and Park, M. 2000. Activation of Cdc42, Rac, PAK, and Rhokinase in response to hepatocyte growth factor differentially regulates epithelial cell colony spreading and dissociation. Mol. Biol. Cell 11: 1709-1725.

Ruberte, E., Marty, T., Nellen, D., Affolter, M., and Basler, K. 1995. An absolute requirement for both the type II and type I receptors, punt and thick veins, for dpp signaling in vivo. Cell 80: 889-897.

Sander, E.E. and Collard, J.G. 1999. Rho-like GTPases: Their role in epithelial cell-cell adhesion and invasion. Europ. J. Cancer 35: 1905-1911.

Sander, E.E., van Delft, S., ten Klooster, J.P., Reid, T., van der Kammen, R.A., Michiels, F., and Collard, J.G. 1998. Matrixdependent Tiam1/Rac signaling in epithelial cells promotes either cell-cell adhesion or cell migration and is regulated by phosphatidylinositol 3-kinase. J. Cell Biol. 143: 1385-1398.

Sander, E.E., ten Klooster, J.P., van Delft, S., van der Kammen, R.A., and Collard, J.G. 1999. Rac downregulates Rho activity: Reciprocal balance between both GTPases determines cellular morphology and migratory behavior. J. Cell Biol. 147: 1009-1022.

Savagner, P. 2001. Leaving the neighborhood: Molecular mechanisms involved during epithelial-mesenchymal transition. BioEssays 23: 912-923.

Schmitz, A.A., Govek, E.E., Bottner, B., and Van Aelst, L. 2000. Rho GTPases: Signaling, migration, and invasion. Exp. Cell Res. 261: 1-12.
Schwartz, M.A. and Shattil, S.J. 2000. Signaling networks linking integrins and rho family GTPases. Trends Biochem. Sci. 25: 388-391.

Self, T., Mahony, M., Fleming, J., Walsh, J., Brown, S.D., and Steel, K.P. 1998. Shaker-1 mutations reveal roles for myosin VIIA in both development and function of cochlear hair cells. Development 125: 557-566.

Selleck, M.A. and Bronner-Fraser, M. 2000. Avian neural crest cell fate decisions: A diffusible signal mediates induction of neural crest by the ectoderm. Int. J. Dev. Neurosci. 18: 621627.

Settleman, J. 2001. Rac 'n Rho: The music that shapes a developing embryo. Dev. Cell 1:321-331.

Shaw, R.J., Henry, M., Solomon, F., and Jacks, T. 1998. RhoAdependent phosphorylation and relocalization of ERM proteins into apical membrane/actin protrusions in fibroblasts. Mol. Biol. Cell 9: 403-419.

Shulman, J.M., Perrimon, N., and Axelrod, J.D. 1998. Frizzled signaling and the developmental control of cell polarity. Trends Genet. 14: 452-458.

Simske, J.S. and Hardin, J. 2001. Getting into shape: Epidermal morphogenesis in Caenorhabditis elegans embryos. BioEssays 23: 12-23.

Sluss, H.K., Han, Z., Barrett, T., Davis, R.J., and Ip, Y.T. 1996. A JNK signal transduction pathway that mediates morphogenesis and an immune response in Drosophila. Genes \& Dev. 10: $2745-2758$.

Stark, K.A., Yee, G.H., Roote, C.E., Williams, E.L., Zusman, S., and Hynes, R.O. 1997. A novel alpha integrin subunit associates with betaPS and functions in tissue morphogenesis and movement during Drosophila development. Development 124: 4583-4594.

Stoker, M. 1989. Effect of scatter factor on motility of epithelial cells and fibroblasts. J. Cell Physiol. 139: 565-569.

Stoker, M., Gherardi, E., Perryman, M., and Gray, J. 1987. Scatter factor is a fibroblast-derived modulator of epithelial cell mobility. Nature 327: 239-242.

Stronach, B.E. and Perrimon, N. 1999. Stress signaling in Drosophila. Oncogene 18: 6172-6182.

- 2002. Activation of the JNK pathway during dorsal closure in Drosophila requires the mixed lineage kinase, slipper. Genes \& Dev. 16: 377-387.

Strutt, D. 2001. Planar polarity: Getting ready to ROCK. Curr. Biol. 11: R506-R509.

Strutt, D.I., Weber, U., and Mlodzik, M. 1997. The role of RhoA in tissue polarity and Frizzled signalling. Nature 387: 292295

Strutt, H. and Strutt, D. 1999. Polarity determination in the Drosophila eye. Curr. Opin. Gen. \& Dev. 9: 442-446.

Su, Y.C., Treisman, J.E., and Skolnik, E.Y. 1998. The Drosophila Ste20-related kinase misshapen is required for embryonic dorsal closure and acts through a JNK MAPK module on an evolutionarily conserved signaling pathway. Genes \& Dev. 12: 2371-2380.

Suzuki, A., Yamanaka, T., Hirose, T., Manabe, N., Mizuno, K. Shimizu, M., Akimoto, K., Izumi, Y., Ohnishi, T., and Ohno, S. 2001. Atypical protein kinase $\mathrm{C}$ is involved in the evolutionarily conserved par protein complex and plays a critical role in establishing epithelia-specific junctional structures. $J$. Cell Biol. 152: 1183-1196.

Symons, M. and Settleman, J. 2000. Rho family GTPases: More than simple switches. Trends Cell Biol. 10: 415-419.

Takaishi, K., Sasaki, T., Kato, M., Yamochi, W., Kuroda, S., Nakamura, T., Takeichi, M., and Takai, Y. 1994. Involvement of Rho p21 small GTP-binding protein and its regulator in the HGF-induced cell motility. Oncogene 9: 273-279. 
Takaishi, K., Sasaki, T., Kotani, H., Nishioka, H., and Takai, Y. 1997. Regulation of cell-cell adhesion by Rac and Rho small G proteins in MDCK cells. J. Cell Biol. 139: 1047-1059.

Tangkijvanich, P., Tam, S.P., and Yee, Jr., H.F. 2001. Woundinduced migration of rat hepatic stellate cells is modulated by endothelin-1 through rho-kinase-mediated alterations in the acto-myosin cytoskeleton. Hepatology 33: 74-80.

Tao, W., Pennica, D., Xu, L., Kalejta, R.F., and Levine, A.J. 2001. Wrch-1, a novel member of the Rho gene family that is regulated by Wnt-1. Genes \& Dev. 15: 1796-1807.

Theisen, H., Purcell, J., Bennett, M., Kansagara, D., Syed, A., and Marsh, J.L. 1994. dishevelled is required during wingless signaling to establish both cell polarity and cell identity. Development 120: 347-360.

Thiery, J.P. and Chopin, D. 1999. Epithelial cell plasticity in development and tumor progression. Cancer Metastasis Rev. 18: 31-42.

Tilney, L.G., Tilney, M.S., and DeRosier, D.J. 1992. Actin filaments, stereocilia, and hair cells: How cells count and measure. Annu. Rev. Cell Biol. 8: 257-274.

Timpson, P., Jones, G.E., Frame, M.C., and Brunton, V.G. 2001. Coordination of cell polarization and migration by the Rho family GTPases requires Src tyrosine kinase activity. Curr. Biol. 11: 1836-1846.

Van Aelst, L. and D'Souza-Schorey, C. 1997. Rho GTPases and signaling networks. Genes \& Dev. 11: 2295-2322.

Vande Woude, G.F., Jeffers, M., Cortner, J., Alvord, G., Tsarfaty, I., and Resau, J. 1997. Met-HGF/SF: Tumorigenesis, invasion and metastasis. Ciba. Found. Symp. 212: 119-130.

Vasioukhin, V. and Fuchs, E. 2001. Actin dynamics and cell-cell adhesion in epithelia. Curr. Opin. Cell Biol. 13: 76-84.

Vasioukhin, V., Bauer, C., Yin, M., and Fuchs, E. 2000. Directed actin polymerization is the driving force for epithelial cellcell adhesion. Cell 100: 209-219.

Vega-Salas, D.E., Salas, P.J., and Rodriguez-Boulan, E. 1987. Modulation of the expression of an apical plasma membrane protein of Madin-Darby canine kidney epithelial cells: Cellcell interactions control the appearance of a novel intracellular storage compartment. J. Cell Biol. 104: 1249-1259.

Viebahn, C. 1995. Epithelio-mesenchymal transformation during formation of the mesoderm in the mammalian embryo. Acta Anat. 154: 79-97.

Vinson, C.R., Conover, S., and Adler, P.N. 1989. A Drosophila tissue polarity locus encodes a protein containing seven potential transmembrane domains. Nature 338: 263-264.

Vleminckx, K., Vakaet, Jr., L., Mareel, M., Fiers, W., and van Roy, F. 1991. Genetic manipulation of E-cadherin expression by epithelial tumor cells reveals an invasion suppressor role. Cell 66: 107-119.

Walsh, S.V., Hopkins, A.M., Chen, J., Narumiya, S., Parkos, C.A., and Nusrat, A. 2001. Rho kinase regulates tight junction function and is necessary for tight junction assembly in polarized intestinal epithelia. Gastroenterology 121: 566-579.

Wang, A.Z., Ojakian, G.K., and Nelson, W.J. 1990. Steps in the morphogenesis of a polarized epithelium. II. Disassembly and assembly of plasma membrane domains during reversal of epithelial cell polarity in multicellular epithelial (MDCK) cysts. J. Cell Sci. 95: 153-165.

Wasserman, S. 1998. FH proteins as cytoskeletal organizers. Trends Cell Biol. 8: 111-115.

Watanabe, N., Madaule, P., Reid, T., Ishizaki, T., Wantanabe, G., Kakizuka, A., Saito, Y., Nakao, K., Jockusch, B.M., and Narumiya, S. 1997. p140mDia, a mammalian homolog of Drosophila diaphanous, is a target protein for Rho small GTPase is a ligand for profilin. EMBO J. 16: 3044-3056.
Watanabe, N., Kato, T., Fujita, A., Ishizaki, T., and Narumiya, S 1999. Cooperation between mDial and ROCK in Rho-induced actin reorganization. Nat. Cell Biol. 1: 136-143.

Waterman-Storer, C.M., Worthylake, R.A., Liu, B.P., Burridge, K., and Salmon, E.D. 1999. Microtubule growth activates Rac1 to promote lamellipodial protrusion in fibroblasts. Nat. Cell Biol. 1: 45-50.

Weber, U., Paricio, N., and Mlodzik, M. 2000. Jun mediates frizzled-induced R3/R4 cell fate distinction and planar polarity determination in the Drosophila eye. Development 127: 3619-3629.

Williams-Masson, E.M., Malik, A.N., and Hardin, J. 1997. An actin-mediated two-step mechanism is required for ventral enclosure of the C. elegans hypodermis. Development 124: 2889-2901.

Winter, C.G., Wang, B., Ballew, A., Royou, A., Karess, R., Axelrod, J.D., and Luo, L. 2001. Drosophila Rho-associated kinase (Drok) links Frizzled-mediated planar cell polarity signaling to the actin cytoskeleton. Cell 105: 81-91.

Wittmann, T. and Waterman-Storer, C.M. 2001. Cell motility: Can Rho GTPases and microtubules point the way? J. Cell Sci. 114: 3795-3803.

Wodarz, A. 2002. Establishing cell polarity in development. Nat. Cell Biol. 4: E39-E44.

Wu, Y.C. and Horvitz, H.R. 1998. C. elegans phagocytosis and cell-migration protein CED-5 is similar to human DOCK180. Nature 392: 501-504.

Wu, Y.C., Tsai, M.C., Cheng, L.C., Chou, C.J., and Weng, N.Y 2001. C. elegans CED-12 acts in the conserved crkII/ DOCK180/Rac pathway to control cell migration and cell corpse engulfment. Dev. Cell 1: 491-502.

Yamanaka, T., Horikoshi, Y., Suzuki, A., Sugiyama, Y., Kitamura, K., Maniwa, R., Nagai, Y., Yamashita, A., Hirose, T., Ishikawa, H., et al. 2001. PAR-6 regulates aPKC activity in a novel way and mediates cell-cell contact-induced formation of the epithelial junctional complex. Genes Cells 6: 721-731.

Yeaman, C., Grindstaff, K.K., and Nelson, W.J. 1999. New perspectives on mechanisms involved in generating epithelial cell polarity. Physiol. Rev. 79: 73-98.

Young, P.E., Richman, A.M., Ketchum, A.S., and Kiehart, D.P. 1993. Morphogenesis in Drosophila requires nonmuscle myosin heavy chain function. Genes \& Dev. 7: 29-41.

Zeitlinger, J., Kockel, L., Peverali, F.A., Jackson, D.B., Mlodzik, M., and Bohmann, D. 1997. Defective dorsal closure and loss of epidermal decapentaplegic expression in Drosophila fos mutants. EMBO I. 16: 7393-7401.

Zhang, X., Bi, E., Novick, P., Du, L., Kozminski, K.G., Lipschutz, J.H., and Guo, W. 2001. Cdc42 interacts with the exocyst and regulates polarized secretion. I. Biol Chem. 276: 46745-46750.

Zheng, J.Q., Wan, J.J., and Poo, M.M. 1996. Essential role of filopodia in chemotropic turning of nerve growth cone induced by a glutamate gradient. I. Neurosci. 16: 1140-1149.

Zhong, C., Kinch, M.S., and Burridge, K. 1997. Rho-stimulated contractility contributes to the fibroblastic phenotype of Ras-transformed epithelial cells. Mol. Biol. Cell 8: 2329-2344.

Zhou, Z., Caron, E., Hartwieg, E., Hall, A., and Horvitz, H.R 2001. The C. elegans $\mathrm{PH}$ domain protein CED-12 regulates cytoskeletal reorganization via a Rho/Rac GTPase signaling pathway. Dev. Cell 1: 477-489.

Zondag, G.C.M., Evers, E.E., ten Klooster, J.P., Janssen, L., van der Kammen, R.A., and Collard, J.G. 2000. Oncogenic Ras downregulates Rac activity, which leads to increased Rho activity and epithelial-mesenchymal transition. J. Cell Biol. 149: 775-781. 


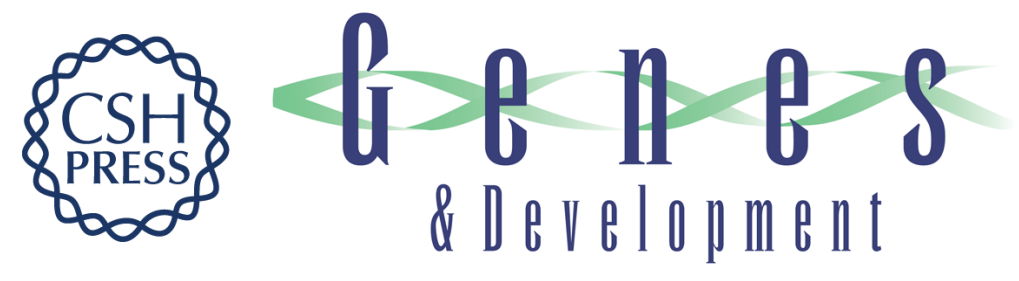

\section{Role of Rho family GTPases in epithelial morphogenesis}

Linda Van Aelst and Marc Symons

Genes Dev. 2002, 16:

Access the most recent version at doi:10.1101/gad.978802

References This article cites 251 articles, 108 of which can be accessed free at: http://genesdev.cshlp.org/content/16/9/1032.full.html\#ref-list-1

License

Email Alerting Receive free email alerts when new articles cite this article - sign up in the box at the top Service right corner of the article or click here.

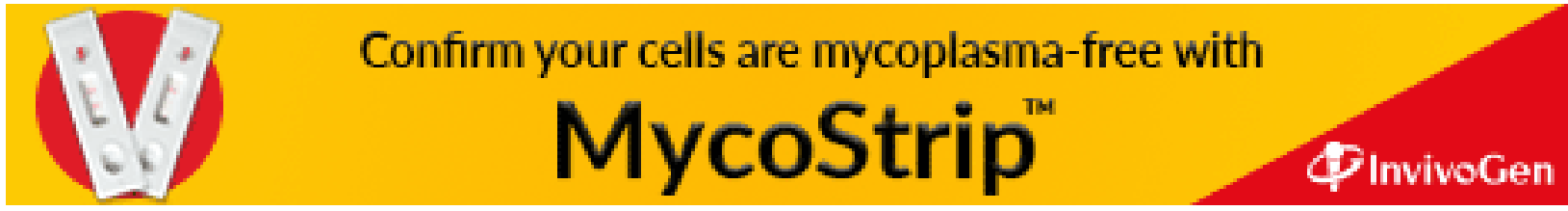

